\title{
Faroe Bank Channel Overflow: Mesoscale Variability*
}

\author{
ELIN DARELIUS AND ILKER FER \\ Geophysical Institute, University of Bergen, and Bjerknes Center for Climate Research, Bergen, Norway \\ DETLEF QUADFASEL \\ University of Hamburg, Hamburg, Germany
}

(Manuscript received 8 February 2011, in final form 8 June 2011)

\begin{abstract}
The Faroe Bank Channel is the deepest connection through the Greenland-Scotland Ridge, where dense water formed north of the ridge flows southward over the sill crest, contributing to the formation of North Atlantic Deep Water. The overflow region is characterized by high mesoscale variability and energetic oscillations, accompanied by a high degree of sea surface level variability. Here, 2-month-long time series of velocity and temperature from 12 moorings deployed in May 2008 are analyzed to describe the oscillations and explore their generation and propagation. The observed 2.5-5-day oscillations in velocity and temperature are highly coherent both horizontally and vertically, and they are associated with 100-200-m-thick boluses of cold plume water flowing along the slope. A positive correlation between temperature and relative vorticity and the distribution of clockwise/counterclockwise rotation across the slope suggest a train of alternating warm cyclonic and cold anticyclonic eddies, where the maximum plume thickness is located downslope of the eddy center. The along-slope phase velocity is found to be $25-60 \mathrm{~cm} \mathrm{~s}^{-1}$, corresponding to a wavelength of $75-180 \mathrm{~km}$, while the vertical phase propagation is downward. The oscillations are present already in the sill region. The observations do not match predictions for eddies generated either by vortex stretching or baroclinic instability but agree broadly with properties of topographic Rossby waves.
\end{abstract}

\section{Introduction}

The southward export of the dense waters formed at high northern latitudes is restricted by the GreenlandScotland Ridge, the submarine mountain range separating the deep basins of the Nordic Seas from the subpolar North Atlantic. Only water at depths shallower than the ridge level can leave the Nordic Seas and contribute to the Atlantic meridional overturning circulation. Most of the density-driven export takes place in the deep overflows through the two deepest passages across the ridge: the Denmark Strait and the Faroe Bank Channel (FBC; see, e.g., Quadfasel and Käse 2007). With a sill depth of $840 \mathrm{~m}$, the FBC is the deepest gap in

\footnotetext{
* Bjerknes Center for Climate Research Publication Number A339.

Corresponding author address: I. Fer, Geophysical Institute, University of Bergen, Allégaten 70, N-5007 Bergen, Norway. E-mail: ilker.fer@gfi.uib.no
}

the ridge, and the transport through the channel accounts for about one-third of the total overflow export from the Nordic Seas (Hansen and Østerhus 2007).

The volume transport of cold overflow water at the sill has been monitored continuously with moored current profilers from 1995 to 2005 (Hansen and Østerhus 2007). The mean kinematic overflow flux (i.e., the volume transport determined from the velocity profiles alone) is $2.1 \mathrm{~Sv}$ $\left(1 \mathrm{~Sv} \equiv 10^{6} \mathrm{~m}^{3} \mathrm{~s}^{-1}\right)$. The mean volume flux of water with a potential density anomaly higher than $27.8 \mathrm{~kg} \mathrm{~m}^{-3}$, the density criterion that is commonly referred to as overflow water (Dickson and Brown 1994), is $1.9 \mathrm{~Sv}$, whereas the mean transport of water colder than $3^{\circ} \mathrm{C}$ is $1.7 \mathrm{~Sv}$ (Hansen and Østerhus 2007). No significant trend is observed during the 10-yr period, but a considerable amount of variability on shorter time scales is found. Daily transport estimates vary between 0.7 and $4.5 \mathrm{~Sv}$, whereas monthly averages range from 1.5 to $2.9 \mathrm{~Sv}$. For further details about the overflow at the sill the reader is referred to review articles by Hansen and Østerhus (2000), Saunders (2001), Borenäs and Lundberg (2004), and Østerhus et al. (2008). 
Downstream of the sill crest, the overflow plume is constricted at both sides by the flanks of the FBC for about $30 \mathrm{~km}$ before the channel widens and the bathymetry steepens toward the deep Iceland Basin (Fig. 1). The plume flows as a bottom-trapped current along the slope of the Iceland-Faroe Ridge, descends to deeper levels, and accelerates locally over steep topography before it decelerates farther downstream. About $100 \mathrm{~km}$ downstream of the sill (close to the mooring array D; Fig. 1 ), velocities exceeding those at the sill are observed (Mauritzen et al. 2005), and this area stands out as a region with intensive mixing (Mauritzen et al. 2005; Fer et al. 2010). Entrainment inferred from turbulence measurements increase by one order of magnitude as the Froude number approaches unity (Fer et al. 2010).

The FBC overflow plume is characterized by energetic, subinertial oscillations, observed already at the sill (Saunders 1990; Hansen and Østerhus 2007). Farther downstream, Geyer et al. (2006) have reported highly regular 88-h oscillations in the records of near-bottom velocity and temperature in the overflow plume. A thermistor string captured 200-m-thick boluses of cold water translating along the slope. The oscillations are probably related to the increased sea level variability observed in the region downstream of the sill (Høyer and Quadfasel 2001). Similar oscillations appear in the regional models of the FBC overflow by Ezer (2006), Riemenschneider and Legg (2007), and Seim et al. (2010).

Comparable mesoscale variability is observed in other overflow regions [e.g., the Denmark Strait Overflow (DSO; Smith 1976) and the Filchner Overflow (Darelius et al. 2009)], as well as in laboratory experiments (Smith 1977; Cenedese et al. 2004; Wåhlin et al. 2008) and numerical models (Jiang and Garwood 1996; Tanaka and Akitomo 2001; Ezer 2006) simulating dense plumes on sloping topography. A number of generation mechanisms has been suggested, often related to baroclinic instabilities (Smith 1976; Swaters 1991), vortex stretching (Lane-Serff and Baines 1998; Spall and Price 1998), or the bathymetry (Nof et al. 2002; Pratt et al. 2008), but as of today no consensus or clear understanding of the origin and nature of these oscillations exist. In the following, we loosely refer to the oscillations as eddies.

Eddies play an important role in the overflow dynamics. They increase the descent rate of the plume (Tanaka and Akitomo 2001; Seim et al. 2010), possibly because growing baroclinic instabilities represent a loss of momentum from the overflow to the overlying ambient (Kida et al. 2009). Eddies may also increase entrainment, through either enhanced vertical mixing (Seim et al. 2010) or horizontal stirring (Voet and Quadfasel 2010). Enhanced entrainment implies enhanced drag or friction and consequently an increased descent rate. Seim and Fer

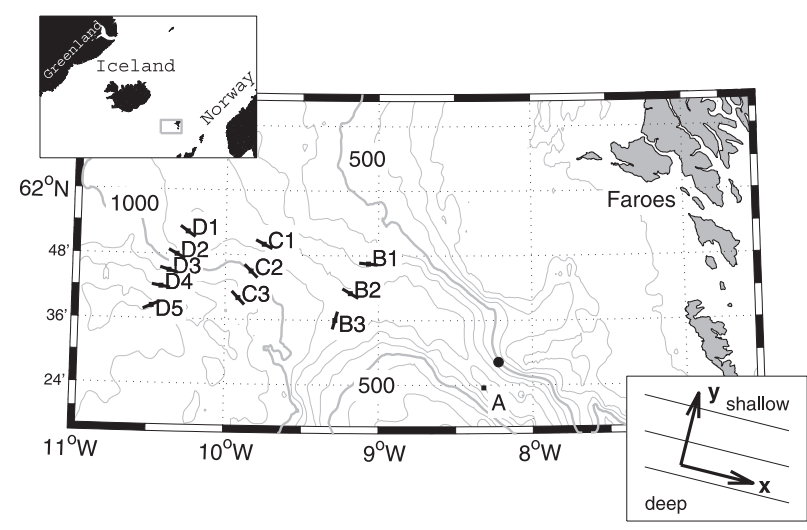

FIG. 1. Map showing the bathymetry of the study region together with the position of the moorings. Isobaths (GEBCO 2003) are shown every $100 \mathrm{~m}$ with the 500- and $1000-\mathrm{m}$ isobaths drawn in bold. The short black lines indicate the orientation of the local isobaths for each mooring marked by small squares. The filled circle indicates the position of the WOCE mooring (Mortensen et al. 2009). The insets show (top) the location of the study area (gray rectangle) and (bottom) the orientation of the coordinate system with respect to local isobaths.

(2011) find that the streamwise pressure gradient is nearly balanced by the bottom stress, and a transverse flow at the plume interface is geostrophically balanced with the streamwise pressure gradient. They find that the mesoscale oscillations significantly affect the transverse circulation, which effectively contributes to mixing.

In this paper, data from moorings deployed during two months in early summer 2008 in three arrays downstream of the FBC sill are analyzed and described, focusing on the properties of the observed mesoscale oscillations. The aim of the study is, to the extent that the observations allow, 1) to gather evidence for or against suggested eddy generation mechanisms and 2) to describe the salient features of the mesoscale variability. Contrary to the previous study by Geyer et al. (2006), which is based on measurements close to the bottom only, this work includes data from moorings extending $250 \mathrm{~m}$ from the bottom, covering a large part of the vertical extent of the plume and reaching well above the bottom boundary layer. Consequently, vertical as well as horizontal properties of the oscillations can be assessed.

\section{Data and methods}

Data were collected in the FBC overflow region using 12 bottom-anchored moorings, in the period 14 May18 July 2008 (Fig. 1). The moorings were equipped with temperature recorders [Sea-Bird Electronics 39 (SBE39) and RBR TR-1050], conductivity-temperature-pressure recorders (SBE37 and Microcats), Anderaa current meters (RCM7/8/11), and acoustic Doppler current profilers 
TABLE 1. Location, echo depth, orientation of local isobath $\beta$, and instrumentation of moorings deployed 14 May 2008 and recovered $18 \mathrm{Jul}$ 2008. Here, $L$ is the representative width of each mooring used in transport calculations. For instrumentation, the target height above bottom is given. Superscripts indicate the following: asterisks indicate that pressure is measured; the numbers 1-31 indicate the percentage of data removed because of instrument tilt (no exponent means no data were removed); and D and U indicate downward and upward looking, respectively. Mooring A was partly lost (see text).

\begin{tabular}{|c|c|c|c|c|c|c|c|c|}
\hline & $\begin{array}{l}\text { Latitude } \\
\text { (N) }\end{array}$ & $\begin{array}{l}\text { Longitude } \\
\text { (W) }\end{array}$ & $\begin{array}{l}\text { Depth } \\
(\mathrm{m})\end{array}$ & $\begin{array}{c}L \\
(\mathrm{~km})\end{array}$ & $\beta$ & $\mathrm{RCM}$ & $\begin{array}{c}\text { SBE37/39 } \\
\text { RBR }\end{array}$ & $\begin{array}{l}\text { ADCP } \\
\text { RDCP }\end{array}$ \\
\hline A & $61^{\circ} 23.5^{\prime}$ & $8^{\circ} 19^{\prime}$ & 835 & - & $-50^{\circ}$ & Lost & lost & $70^{\mathrm{D}}$ \\
\hline B1 & $61^{\circ} 46.5^{\prime}$ & $9^{\circ} 4^{\prime}$ & 686 & 11.0 & $-6^{\circ}$ & - & $\begin{array}{c}120 / 110 / 90 / 80 \\
79 / 60 * / 40 / 30\end{array}$ & $20^{\mathrm{U}}$ \\
\hline B2 & $61^{\circ} 41^{\prime}$ & $9^{\circ} 11^{\prime}$ & 804 & 11.3 & $-31^{\circ}$ & $100 / 20$ & $\begin{array}{c}201 / 200 / 190 / 180 \\
170 / 160 / 150^{*} \\
148 / 140 / 101 / 21\end{array}$ & $210^{\mathrm{D}}$ \\
\hline B3 & $61^{\circ} 36^{\prime}$ & $9^{\circ} 17^{\prime}$ & 812 & 10.4 & $-106^{\circ}$ & $70 / 20^{1}$ & $80 / 70 * / 60 / 50 / 20$ & - \\
\hline $\mathrm{C} 1$ & $61^{\circ} 50^{\prime}$ & $9^{\circ} 45^{\prime}$ & 855 & 10.1 & $-28^{\circ}$ & $149 / 20^{2}$ & $\begin{array}{c}150 * / 100 / 80 * \\
78 / 60 / 20\end{array}$ & $50^{\mathrm{U}}$ \\
\hline $\mathrm{C} 2$ & $61^{\circ} 45^{\prime}$ & $9^{\circ} 50^{\prime}$ & 990 & 10.2 & $-46^{\circ}$ & $160 / 20^{31}$ & $100 * / 98 / 70 * / 60 / 21$ & $50^{\mathrm{U}}$ \\
\hline C3 & $61^{\circ} 40^{\prime}$ & $9^{\circ} 55^{\prime}$ & 1122 & 10.1 & $-48^{\circ}$ & $20^{37 *}$ & $150 * / 100 / 60 / 20$ & - \\
\hline D1 & $61^{\circ} 52^{\prime}$ & $10^{\circ} 15^{\prime}$ & 809 & 9.3 & $-37^{\circ}$ & 18 & $19^{*}$ & - \\
\hline D2 & $61^{\circ} 48^{\prime}$ & $10^{\circ} 19^{\prime}$ & 913 & 7.4 & $-30^{\circ}$ & $119 / 18^{*}$ & $140 * / 69$ & - \\
\hline D3 & $61^{\circ} 45^{\prime}$ & $10^{\circ} 22^{\prime}$ & 1062 & 6.2 & $-19^{\circ}$ & $\begin{array}{c}240 / 139 * \\
18\end{array}$ & $\begin{array}{c}291 * / 190 / 99 \\
59 / 19\end{array}$ & - \\
\hline D4 & $61^{\circ} 42^{\prime}$ & $10^{\circ} 25^{\prime}$ & 1205 & 6.8 & $-12^{\circ}$ & $\begin{array}{c}240^{2} / 139^{* 2} \\
18^{1}\end{array}$ & $\begin{array}{c}291 * / 190 / 99 / 19 \\
-\end{array}$ & - \\
\hline D5 & $61^{\circ} 38^{\prime}$ & $10^{\circ} 29^{\prime}$ & 1358 & 8.7 & $22^{\circ}$ & $119^{2} / 18^{* 1}$ & $140 * / 69$ & - \\
\hline
\end{tabular}

[ADCPs; RD-Instruments (RDI) 300-kHz Workhorse and Anderaa $600-\mathrm{kHz}$ RDCP]. Instrumentation and location of the moorings are listed in Table 1 . The sampling rate was set to $1 \mathrm{~min}$ for SBE and RBR, 5 min for ADCPs, and 10 min for RCMs. The RDI ADCPs averaged 50 ensembles and profiled at 2-m vertical depth bins. The Andreaa RDCP sampled every 20 min an ensemble of 200 pings collected in burst mode for 2 min with 2-m vertical resolution. Mooring A, located at the sill crest, was lost, but the flotation, containing a downward-looking RDI ADCP, was recovered in northern Norway returning velocity data from the sill region for the period 30 May-30 June.

The coordinate system for each mooring is aligned with the local isobath, so that the $x$ axis points along the isobath and the $y$ axis points upslope (see Fig. 1). The angle of rotation ( $\beta$; Table 1 ) was found using the General Bathymetric Chart of the Oceans (GEBCO 2003) bathymetry smoothed over $10 \mathrm{~km}$, which is comparable to the baroclinic Rossby radius of the dense flow $(6-10 \mathrm{~km})$.

Arrays $\mathrm{B}$ and $\mathrm{C}$ experienced significant vertical displacements during swift currents, whereas the array D moorings were relatively stiff. Time series of the vertical position and tilt of the instruments in arrays $\mathrm{B}$ and $\mathrm{C}$ were calculated using the hourly averaged measured currents following Dewey (1999). The results compared well with the available pressure measurements (not shown). The vertical positions of the instruments at array D were calculated based on available pressure measurements using linear interpolation. Hourly averaged velocity and temperature records were then interpolated linearly onto a vertical grid with $1-\mathrm{m}$ vertical resolution using the inferred instrument depths. When not otherwise stated, calculations are based on this gridded dataset. The higherfrequency near-inertial and tidal variability is removed using a 10th-order Butterworth low-pass filter with a 48-h cutoff period. The filter order is high, but it has a stable frequency response and the desired sharp cutoff. All filtered time series are visually inspected and are found to be free of ringing or edge effects. All velocity data have been corrected for a magnetic deviation of $9^{\circ} \mathrm{W}$.

The strong currents in the region occasionally caused the instruments to tilt more than the threshold value allowed for acceptable measurements, $15^{\circ}$ for RDI ADCPs and $12^{\circ}$ for RCM. For the RCMs, a gymbal on the frame compensates for a tilt of up to $27^{\circ}$ so that the practical threshold is $39^{\circ}$. Data from periods with too large a tilt are excluded from the analysis, causing a bias toward lower velocities because large tilt is correlated with swift currents. This error can be large at C2 and C3 (20 mab), where approximately one-third of the observations are excluded. The percentage of data discarded for each current meter is listed in Table 1.

In addition to mooring data, CTD and lowered-ADCP (LADCP) profiles were collected during the deployment cruise onboard R/V Håkon Mosby between 29 May and 8 June 2008. A total of 63 CTD-LADCP casts were made [see Fer et al. (2010), who discuss turbulence measurements from the same cruise]. The collected CTD profiles 


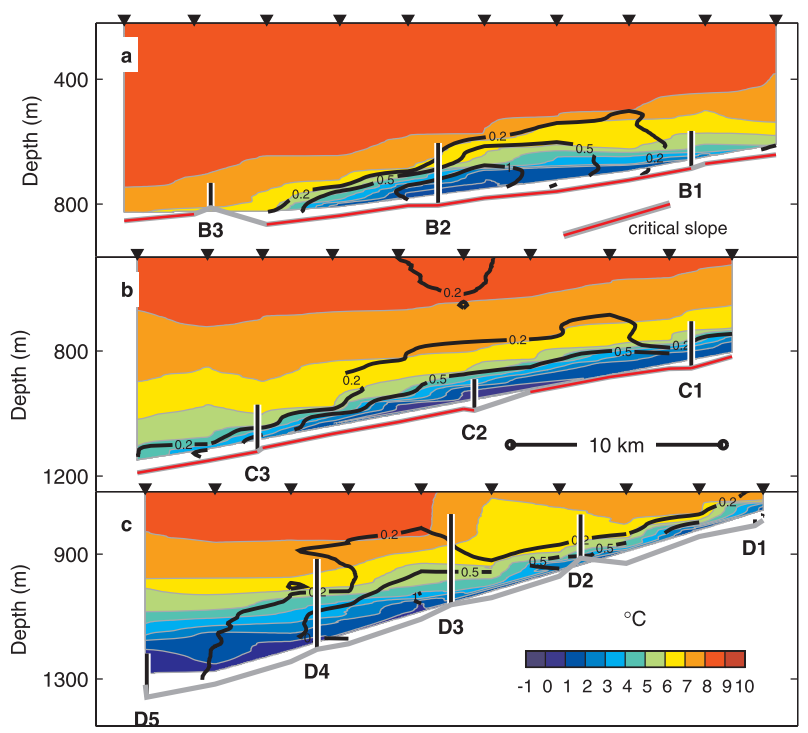

FIG. 2. Position and vertical extent of moorings superimposed on temperature (in color) and along-slope currents (black contours; $\mathrm{m} \mathrm{s}^{-1}$ ) at time of deployment for (a) array B, (b) array C, and (c) array D. Black triangles mark the position of CTD/LADCP profiles. Vertical and horizontal scales in (b) are identical for all panels. The critical slope defined by Nof et al. (2002) is shown in (a). Eddies are expected to occur where the slope is subcritical (marked with red).

show a tight relationship between potential temperature $\theta$ and potential density anomaly $\sigma_{\theta}$ in the overflow region, and density can be inferred from the moored temperature records using $\sigma_{\theta}=-\left(2.0 \times 10^{-4}\right) \theta^{3}-\left(2.2 \times 10^{-3}\right) \theta^{2}-$ $\left(4.09 \times 10^{-2}\right) \theta+28.0414$. This relation captures the observed $\sigma_{\theta}$ to within a root-mean-square (rms) error of 0.009 and $0.007 \mathrm{~kg} \mathrm{~m}^{-3}$ for CTD profiles collected during mooring deployment and recovery, respectively, indicating that the fit is good and stable during the mooring period. Figure 2 shows the relative position of the moorings superimposed on CTD/LADCP sections taken along the mooring arrays. Note that the cold water in the deep part of section $\mathrm{D}$, below the plume, is from the basinwide background stratification.

\section{Mesoscale oscillations}

The temperature and velocity records from all moorings on the Faroe Islands slope are dominated by subinertial, nontidal oscillation with an apparent period of 3-4 days. Figure 3 shows an example of data collected $100 \mathrm{~m}$ above bottom (mab) from mooring D4, situated at $1205-\mathrm{m}$ depth. Here, the oscillation is strongest in $u$, with an amplitude of about $25 \mathrm{~cm} \mathrm{~s}^{-1}$. The temperature record cooscillates, alternating between cold $\left(0^{\circ}-2^{\circ} \mathrm{C}\right)$ and warmer $\left(3^{\circ}-6^{\circ} \mathrm{C}\right)$ water. Although the nature of the mesoscale

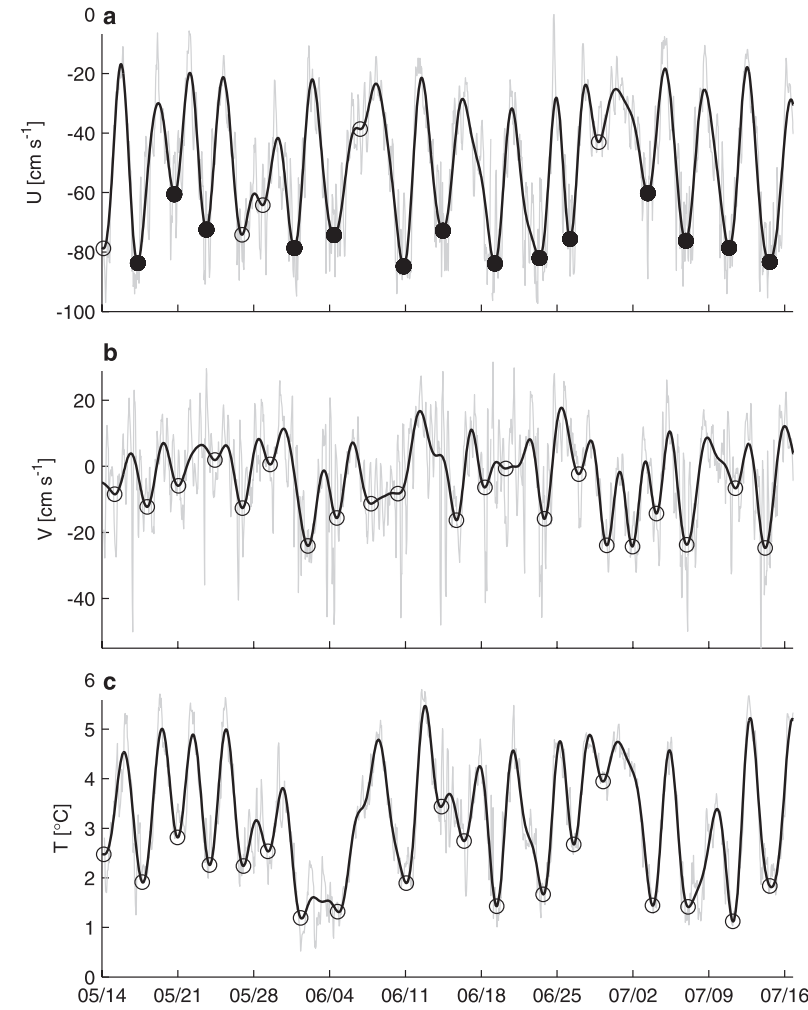

FIG. 3. Time series of (a) along-slope $u$ and (b) across-slope $v$ velocity and (c) temperature acquired by instruments $100 \mathrm{mab}$ at D4 (bottom depth $1205 \mathrm{~m}$ ). Hourly time series (gray) are low passed with a cutoff period of $48 \mathrm{~h}$ (black). Dominant subinertial oscillations (located by negative maxima in $u, v$, and $T$ ) are indicated by circles. The events marked by filled circles in (a) are included in the ensemble average (see section $3 b$ ).

oscillations is uncertain, they will hereafter loosely be referred to as eddies. In the following sections, the properties of the eddies on the slope will be explored.

\section{a. Horizontal and vertical structure}

Figure 4 shows how the temperature and velocity change with time in the horizontal across the slope and in the vertical at array C. For clarity, only 12 days from the period with uniform oscillations (see section $3 \mathrm{i}$ below) are shown. During this period, four boluses of cold water move past the array, heaving the $3^{\circ} \mathrm{C}$ isotherm (at C2) from zero to about 120 mab. The velocity anomalies show a coherent pattern both horizontally and vertically, with low temperatures corresponding to downslope motion and high temperatures corresponding to upslope motion. In addition, current vectors are generally convergent (i.e., crossing each other) when the observed temperature is high, whereas they are divergent (i.e., spreading out) during cold periods. Foldvik et al. (1988) show that convergent and divergent vector patterns recorded by moored current 




FIG. 4. Hovmöller diagram of temperature $\left({ }^{\circ} \mathrm{C}\right)$ according to the color bar in the top right, at (a) the bottom (20 mab) of array $\mathrm{C}$ and (b) at mooring $\mathrm{C} 2$. The distance between moorings $\mathrm{C} 1$ and $\mathrm{C} 2$ and between moorings $\mathrm{C} 2$ and $\mathrm{C} 3$ is $10 \mathrm{~km}$. Low-passed velocity anomalies at $100 \mathrm{mab}(20 \mathrm{mab}$ at C3) in (a) and at 20, 60, and 120 mab in (b) are superimposed (black lines) together with the timeaveraged currents at those levels (white arrows). White diamonds in the vertical axis of (b) show the target height above bottom of temperature sensors at mooring $\mathrm{C} 2$. Note the different velocity scale in (a) and (b).

meters correspond to counterclockwise (CCW; or cyclonic in the Northern Hemisphere) and clockwise (CW; or anticyclonic) eddies propagating past the instrument, respectively. Figure 4 hence suggests that alternating warm and cyclonic eddies and cold and anticyclonic eddies are moving past the array. The sense of rotation locally at the mooring is mostly counterclockwise at $\mathrm{C} 2$ and $\mathrm{C} 3$, whereas it is rectilinear (perpendicular to the mean current) at $\mathrm{C} 1$, which is located higher up on the slope. The varying vertical extent of the measurements evident in Fig. $4 \mathrm{~b}$ is caused by the knockdown of the mooring line during periods of strong currents and high drag. At C3, where the uppermost temperature measurements are well above the cold plume, the temperature records within and above the plume oscillate out of phase: that is, decreasing temperature recorded by

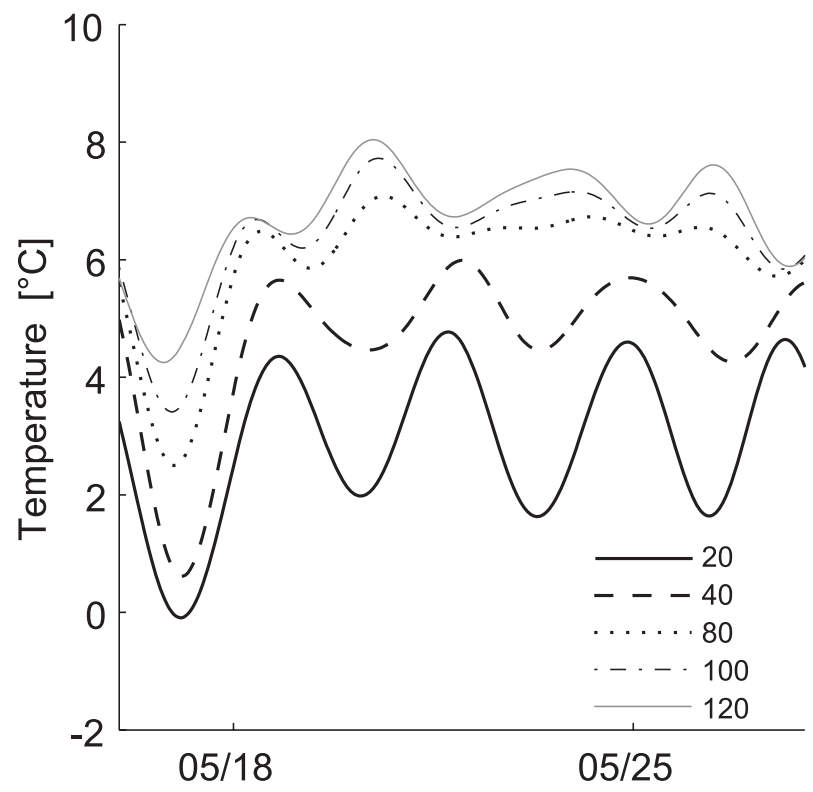

FIG. 5. Low-passed temperature at C3. Legend indicates the mean instrument level as height above bottom (m).

the deeper instruments is associated with an increase in temperature at shallower instruments, situated above the dense outflow. (Fig. 5). This pattern is reminiscent of the oscillations observed within the Filchner Overflow, Antarctica (Darelius et al. 2009).

Figure 4 suggests that the amplitude of the oscillations and thus the eddy kinetic energy (EKE) associated with them vary both horizontally and vertically. EKE of the flow is defined as

$$
\mathrm{EKE}=\frac{1}{2}\left(\overline{u^{\prime 2}}+\overline{v^{\prime 2}}\right)=\int_{0}^{\infty}\left(\Theta_{u}+\Theta_{v}\right) d f
$$

where $u^{\prime}=u-\bar{u}$ and $v^{\prime}=v-\bar{v}$ are the velocity fluctuations, an overbar indicates time averaging, and $\Theta$ is the power spectral density. The energy contribution from the oscillations at the frequency band of interest obtained by integration

$$
\mathrm{EKE}^{*}=\int_{f_{1}}^{f_{2}}\left(\Theta_{u}+\Theta_{v}\right) d f,
$$

where $f_{1}=1 / 5$ cycles per day (cpd) and $f_{2}=1 / 2 \mathrm{cpd}$. Figure $6 \mathrm{a}$ shows the mean EKE* for arrays A-D. The EKE* is highest at array $\mathrm{B}$, and it decreases with increased distance from the sill, as observed by Geyer et al. (2006). The oscillation is present but less energetic at mooring A, which is located upstream of the sill. With the exception of B3 and D5, which are both located at the downslope side of the plume, the energy increases with 

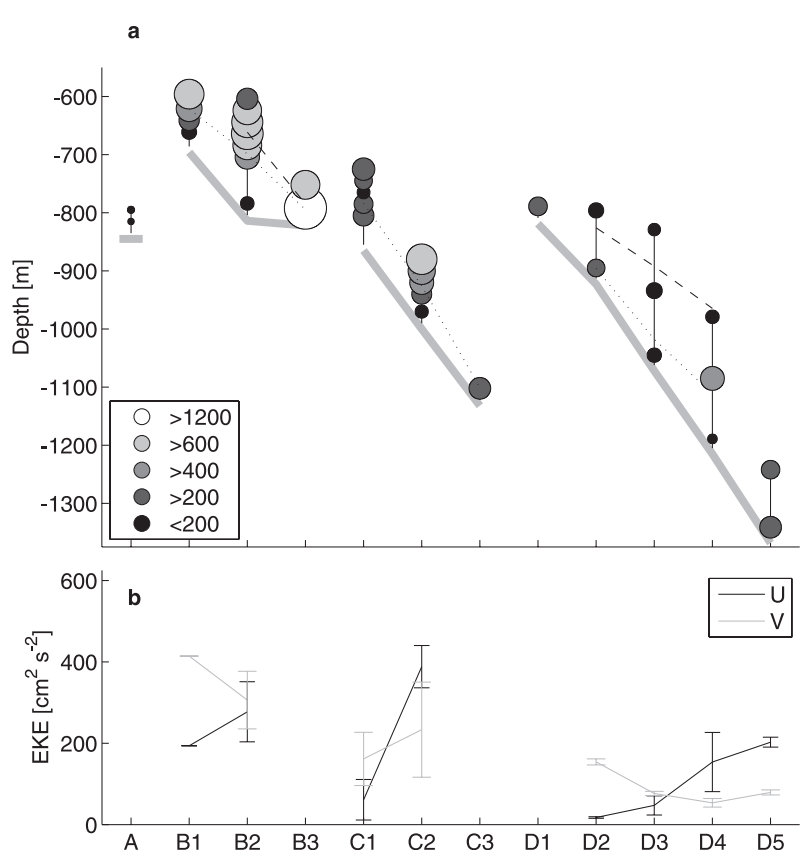

FIG. 6. (a) Mean EKE ( $\mathrm{cm} \mathrm{s}^{-1}$ ) obtained from Fourier analysis in the band of 2.5-5 days at mooring arrays A-D. The energy at a certain depth is proportional to the area of the circle centered at that depth. The mean position of the $3^{\circ}$ (dotted) and $6.5^{\circ} \mathrm{C}$ (dashed) isotherms is indicated. Lack of an isotherm means that it is located above the uppermost recorder for more than $25 \%$ of the time. (b) Mean EKE above the bottom boundary layer $(80 \mathrm{~m})$ for the $u$ and $v$ components.

height above bottom to reach, in the cases where the velocity measurements extend above the plume (B2 and D4), a local maximum. Moorings at the downslope side of the plume (B3, C3, and D5) have relatively high EKE* close to the bottom. The mean (above $80 \mathrm{mab}$ ) repartition of $\mathrm{EKE}^{*}$ between the $u$ and $v$ component is shown in Fig. 6b. EKE* on the upslope part of the plume is dominated by the across-slope components, whereas the along-slope component dominates on the downslope side.

\section{b. Mean eddy properties}

The time-height evolution of a typical eddy is inferred, for each mooring, by ensemble averaging significant eddy events. An ensemble is calculated in a \pm 2 -day window, using at least 6 events, centered at times of maximum outflow (i.e., negative peaks in $u$ ). Outflow peaks are selected when the low-passed $u$ amplitude exceeds 0.7 times its time-mean amplitude. Events that fulfill this criterion are marked in Fig. 3a for mooring D4. A representative ensemble-averaged structure is shown for B1 (Fig. 7). The thickness of the plume, which is here defined as the height of the $3^{\circ} \mathrm{C}$ isotherm, increases from $60 \mathrm{~m}$ to above $100 \mathrm{~m}$ when an eddy passes. The velocity anomaly increases with height and reaches

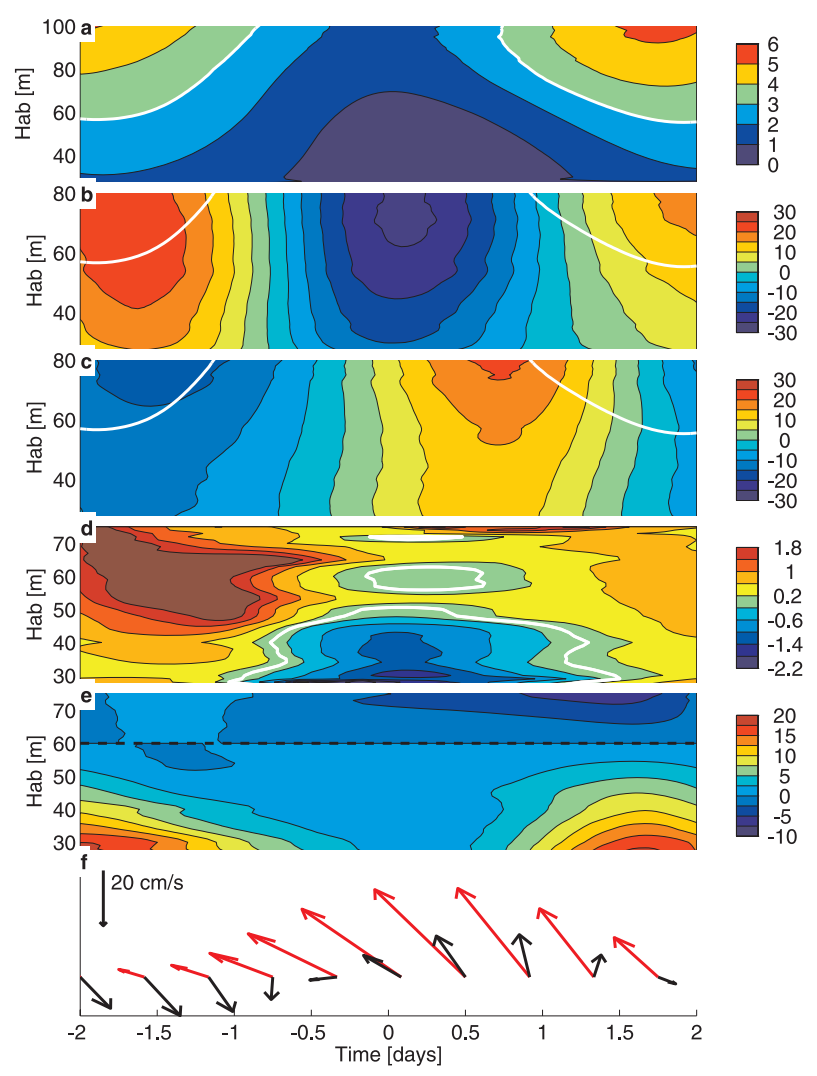

FIG. 7. Ensemble average properties inferred from oscillations at B1: (a) temperature $\left({ }^{\circ} \mathrm{C}\right)$, (b) along-slope velocity $u$, (c) acrossslope velocity $v\left(\mathrm{~cm} \mathrm{~s}^{-1}\right)$, (d) 10-base logarithm of Richardson number, (e) veering $\left({ }^{\circ}\right.$ ), and (f) current (red arrows) and current anomalies (black arrows) at $60 \mathrm{mab}$ (reference level for veering). The white line in (a)-(c) marks the $3^{\circ} \mathrm{C}$ isotherm, and the critical Richardson number $\mathrm{Ri}=1$ in (d). Positive values in (e) indicate veering to the left relative to the reference level (60 mab), which is marked with a dashed line.

an amplitude of about $30 \mathrm{~cm} \mathrm{~s}^{-1}$ at the uppermost measurement level at 80 mab. The mean current, on the other hand, reaches a maximum of $45 \mathrm{~cm} \mathrm{~s}^{-1}$ at $60 \mathrm{mab}$, and the current thus never reverses (Fig. 7f). Maximum eddy outflow velocity coincides with maximum plume thickness, and the velocity vector rotates clockwise.

As the eddy passes, the stratification, the velocity shear, and hence the gradient Richardson number are modulated (Fig. 7d). The Richardson number $\mathrm{Ri}=N^{2} /\left[(\partial u / \partial z)^{2}+\right.$ $\left.(\partial v / \partial z)^{2}\right] \approx\left(-g \Delta \sigma_{\theta} / \rho_{0} \Delta z\right) /\left[(\Delta u / \Delta z)^{2}+(\Delta v / \Delta z)^{2}\right]$ is calculated at each time step using the potential density anomaly profiles derived from the ensemble mean temperature profiles (Fig. 7a) and $\Delta z=10 \mathrm{~m}$. During the outflow peaks, shear dominates and the $\mathrm{Ri}$ is critical $(\mathrm{Ri}<1)$, whereas relatively high values of $\mathrm{Ri}$ are measured before and after the passage of the eddy. A similar pattern, although with different timing, is observed at other moorings where highresolution velocity measurements are available. 


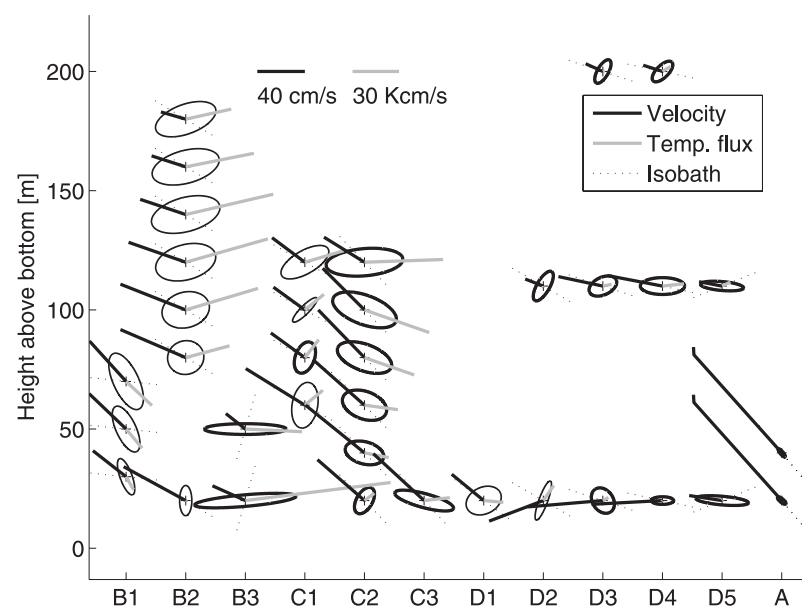

FIG. 8. Principal axes (black ellipses), mean currents (black lines), and temperature fluxes (gray lines) observed at the moorings. CW and CCW rotation of the velocity vector is indicated by thin and thick lines in the ellipse, respectively.

The veering (i.e., the change in flow direction with depth) is affected by the passing eddies. During the outflow peak, when the eddy velocity is aligned with the mean current (Fig. 7f), the current direction is quasi homogeneous below $60 \mathrm{~m}$. Prior to and after the peak, the velocity veers about $20^{\circ}$ to the left toward the bottom. B1 is the only mooring with high-resolution velocity measurements in the bottom boundary layer.

\section{c. Principal axis and rotation}

The orientation of the principal axis (PA) associated with the oscillations at each mooring and depth is found by rotating the components until the maximum in variance is reached in the frequency band corresponding to periods between 2.5 and 5 days (Fig. 8). The oscillations are (mainly) cross isobath at moorings $\mathrm{B} 1, \mathrm{~B} 3, \mathrm{C} 1$, and $\mathrm{D} 2$ and along isobath at moorings $\mathrm{C} 2, \mathrm{C} 3$ and $\mathrm{D} 4$, suggesting across-isobath motion on shallow moorings and along-isobath motion on deep moorings. Note that the oscillation at B1 is aligned with the mean current, which is not aligned with the isobath. At mooring $\mathrm{A}$, close to the sill, the oscillation is aligned with the mean current and directed along the isobath (i.e., across the sill).

The direction of rotation of the velocity vector is found by comparing the phase of $u$ and $v$ obtained from the sinusoidal fits to the low-passed velocity records in May when the oscillations have a relatively constant period (section 3i). The sense of rotation is $\mathrm{CW}$ at $\mathrm{B} 1$, $\mathrm{B} 2, \mathrm{C} 1$, and D1 and CCW at B3, C2, C3, D3, D4 and D5, suggesting CW motion on the upper part of the slope and CCW motion on the lower part. The phase difference between $u$ and $v$ generally increases with height for $\mathrm{CW}$ motion, whereas it decreases for CCW motion.

\section{d. Vertical velocity}

The ADCP at B2, installed in a spherical buoy at 210 mab, experienced negligible tilt and provided good quality record of the vertical velocity $w$ at the interfacial layer between 130 and 200 mab. The subinertial oscillations are observed at all levels, and in this limited range there is no discernible vertical phase propagation. When averaged between 130 and 200 mab, the amplitude of the oscillations is $0.8-1 \mathrm{~cm} \mathrm{~s}^{-1}$ and the timedepth mean vertical velocity is $-0.75 \pm 0.08 \mathrm{~cm} \mathrm{~s}^{-1}$, directed downward. The coherence of $w$ with $u, v$, and $T$ depth averaged over the same interval $\left(\mathrm{coh}_{w u}, \operatorname{coh}_{w v}\right.$, and $\operatorname{coh}_{w T}$, respectively) at the frequencies of interest are significant and very high $(\approx 0.9$ for all pairs $)$ with phases of $\phi_{w u}=32^{\circ}, \phi_{w v}=33^{\circ}$, and $\phi_{w T}=2^{\circ}$, respectively. Maximum downward velocities occur at minimum temperatures, whereas $w$ lags $u$ and $v$ with about $1 / 10$ of a period.

The ADCP at A, near the sill crest, was installed in a low-drag flotation at 70 mab looking downward and returned a good quality record of $w$ in the bottom $70 \mathrm{~m}$. Average pitch and roll values are $1^{\circ}$ and $1.6^{\circ}$, respectively, with a standard deviation of $0.3^{\circ}$. The average temperature at the instrument level (about $70 \mathrm{mab}$ ) is $-0.45^{\circ} \mathrm{C}$, and the sampled data are always in the cold water layer. In contrast to B2, the average vertical velocity at $\mathrm{A}$ is 2.4 $\pm 0.5 \mathrm{~cm} \mathrm{~s}^{-1}$, directed upward, consistent with a secondary circulation and a convergent Ekman transport in the bottom boundary layer on the right side of the channel. The time series of 48-h low-passed, depth-averaged (between 24 and 58 mab, eighteen 2-m-thick bins) vertical velocity is shown in Fig. 9 together with the along- (negative values are outflow) and across-isobath components of the horizontal velocity. The amplitude of the oscillation (in $w$ ) is comparable to that of $\mathrm{B} 2\left(0.5-1 \mathrm{~cm} \mathrm{~s}^{-1}\right)$. Coherence and phase distribution shows significant coherence between vertical and horizontal velocity at periods between 2.4 and 4 days with $\operatorname{coh}_{w u}=0.97, \operatorname{coh}_{w v}=0.67$, $\phi_{w u}=170^{\circ}$, and $\phi_{w v}=141^{\circ}(u$ and $v$ leading $w$ ). The along-slope (i.e., across the sill) component $u$ is nearly $180^{\circ}$ out of phase with $w$, suggesting that strong overflow events (negative $u$ ) are associated with heaving of the plume interface.

\section{e. Eddy temperature flux}

The cooscillation of temperature and velocity (apparent, e.g., in Figs. 3, 4) suggests that there is a net horizontal temperature flux associated with the eddies (i.e., that the eddies are redistributing heat). The horizontal components of the eddy temperature flux are calculated as $Q_{T}=\left(\overline{u^{\prime} T^{\prime}}, \overline{v^{\prime} T^{\prime}}\right)$, where $u^{\prime}, v^{\prime}$, and $T^{\prime}$ represent the contribution from low-frequency variability 


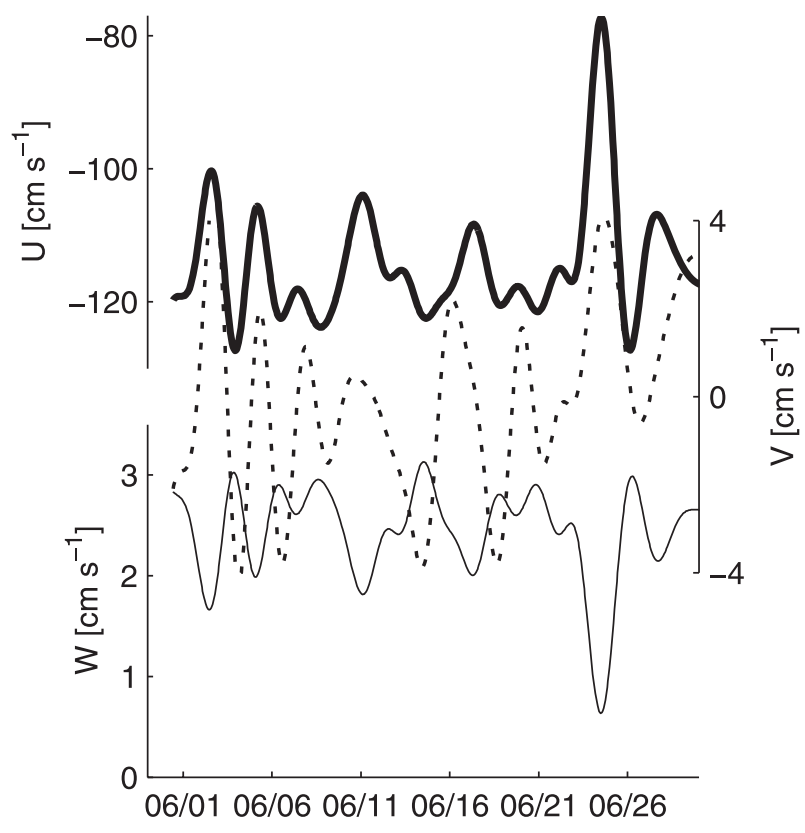

FIG. 9. The 48-h low-passed time series of the velocity components measured at the sill by a downward-looking RDI ADCP installed in a low-drag flotation. The horizontal velocity components $u$ (thick line) and $v$ (dashed line) use the coordinate system shown in Fig. 1, and the outflow is hence given by negative $u$, whereas $v$ shows flow parallel to the sill. Vertical velocity $w$ (thin line) is positive upward. All components are averaged vertically over records from 777- 811-m depths (24-58 mab; i.e., eighteen 2-m-thick bins).

(e.g., $u^{\prime}=u_{\mathrm{LP}}-\bar{u}$, where $u_{\mathrm{LP}}$ is the low-passed time series). Above the bottom boundary layer and with the exemption of the small flux at $\mathrm{D} 2, Q_{T}$ has a component directed to the right of the mean current at all moorings (Fig. 8). The magnitude of the temperature fluxes ranges between 1 and $43 \mathrm{~K} \mathrm{~cm} \mathrm{~s}^{-1}$, of which $1-25 \mathrm{~K} \mathrm{~cm} \mathrm{~s}^{-1}$ is in the direction perpendicular to the mean current and where the largest values are found at $\mathrm{B} 2, \mathrm{C} 2$, and $\mathrm{C} 3$. The eddy temperature flux is hence much larger than that in the DSO, where $Q_{T}$ is about $1 \mathrm{~K} \mathrm{~cm} \mathrm{~s}^{-1}$ or lower (Voet and Quadfasel 2010). It should be noted, however, that the DSO measurements were made farther downstream, more than $200 \mathrm{~km}$ from the sill. Both the temperature difference and the EKE* observed in the DSO is smaller than in the FBC. The temperature flux is consistently directed upstream, indicating that the eddies play a role in transporting cold overflow water downstream.

\section{f. Vorticity}

The relative vorticity $(\xi=\partial v / \partial x-\partial u / \partial y \approx \Delta v / \Delta x-$ $\Delta u / \Delta y)$ is estimated using the low-passed velocity anomalies measured at $100 \mathrm{mab}$ from two triangle configurations of moorings: $\mathrm{T} 1$ formed by $\mathrm{C} 1 / \mathrm{C} 2 / \mathrm{D} 2$ and $\mathrm{T} 2$ formed by $\mathrm{C} 2 / \mathrm{D} 2 / \mathrm{D} 3$. The relative vorticity oscillates
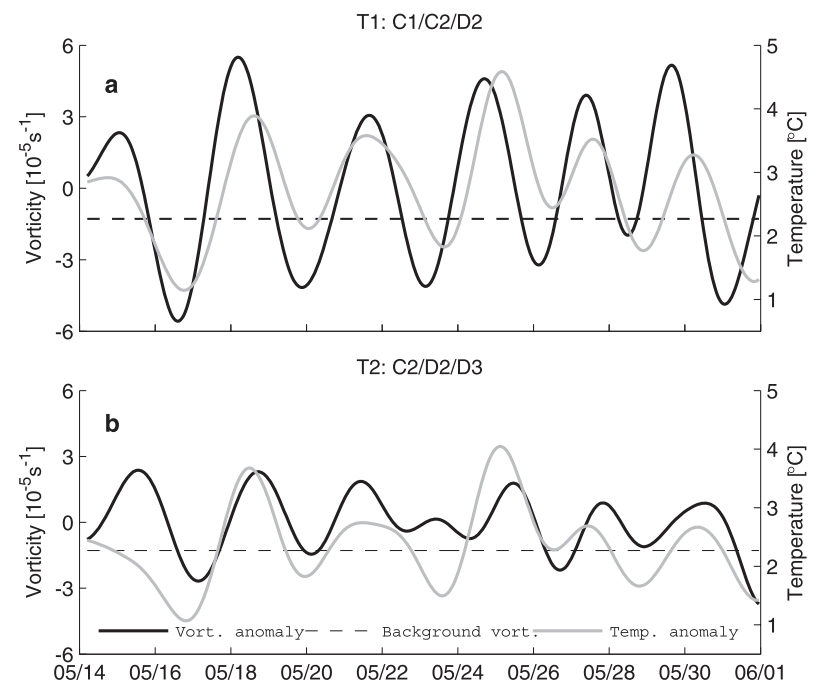

FIG. 10. Relative vorticity $\xi$ anomaly from $100 \mathrm{mab}$ (black line) and background vorticity (dashed line) and mean temperature anomaly from $30 \mathrm{mab}$ (gray line) for mooring triangle (a) T1 (C1/ C2/D2) and (b) T2 (C2/D2/D3).

around zero at the same frequency as the oscillations in temperature and velocity described above (Fig. 10). There is a significant, positive correlation with the triangle mean temperature records from 30 mab (correlation coefficient is $0.61 / 0.65$ for $\mathrm{T} 1 / \mathrm{T} 2)$. Cyclonic motion $(\xi>0)$ and anticyclonic motion $(\xi<0)$ hence coincide with the presence of warm and cold water, respectively, as suggested by the vector patterns in Fig. 3 . The mean background relative vorticity is negative for both triangle configurations and smaller than the amplitude of the oscillations.

\section{g. Phase propagation}

The phase $\phi=k(x-c t)$, where $k$ is the wavenumber and $c$ the phase speed, increases in the direction of propagation and decreases with time. The difference in phase, $\Delta \phi=\phi\left(x, t_{0}\right)-\phi\left(x_{\text {ref }}, t_{0}\right)$, between records with increasing vertical or horizontal separation is found using coherence and phase spectra, and the results are used to estimate the wavelength and phase speed associated with the low-frequency oscillations. Coherence and phase difference are averaged in the frequency band corresponding to periods between 2.5 and 5 days. In records with a welldefined narrowband coherence peak, the width of the frequency band is adapted accordingly. The phase velocities are estimated from the slope of linear fit of phase difference against height or horizontal distance. Only data above the bottom boundary layer are considered.

In the vertical, the coherence in the across-slope component $v$ is very high $(>0.8)$ and $\Delta \phi$ increases approximately linear with height at B2 and C2 (Fig. 11), 
B2
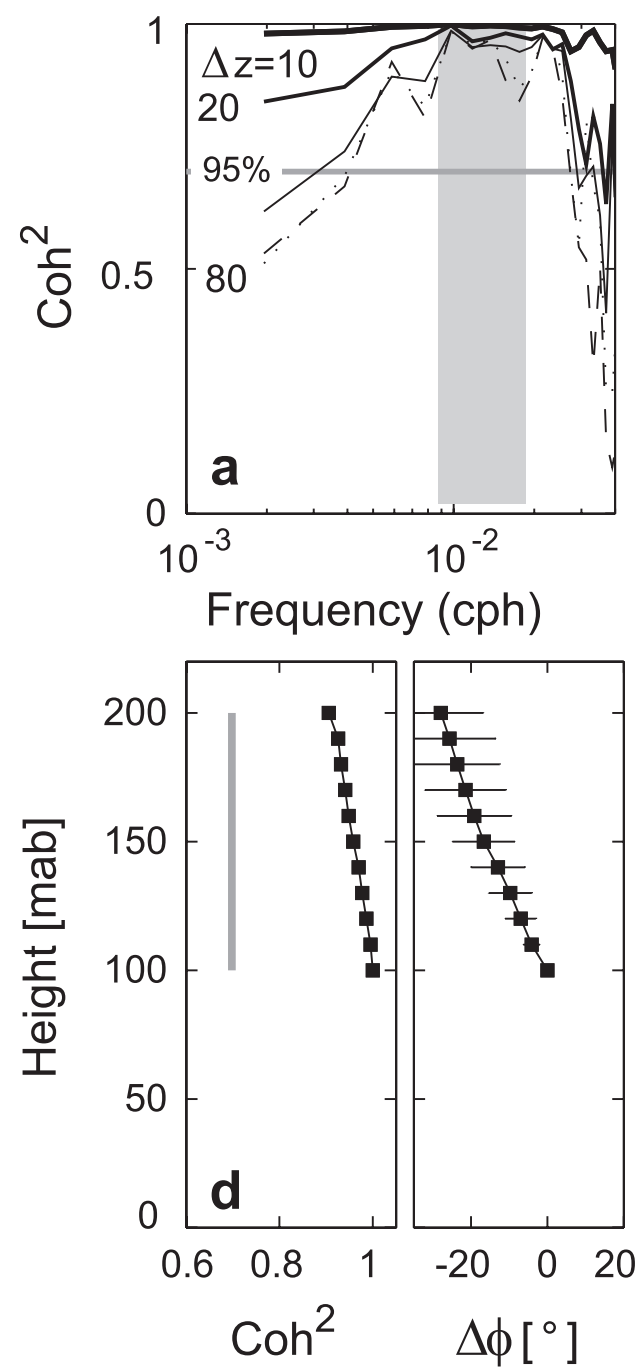

C2
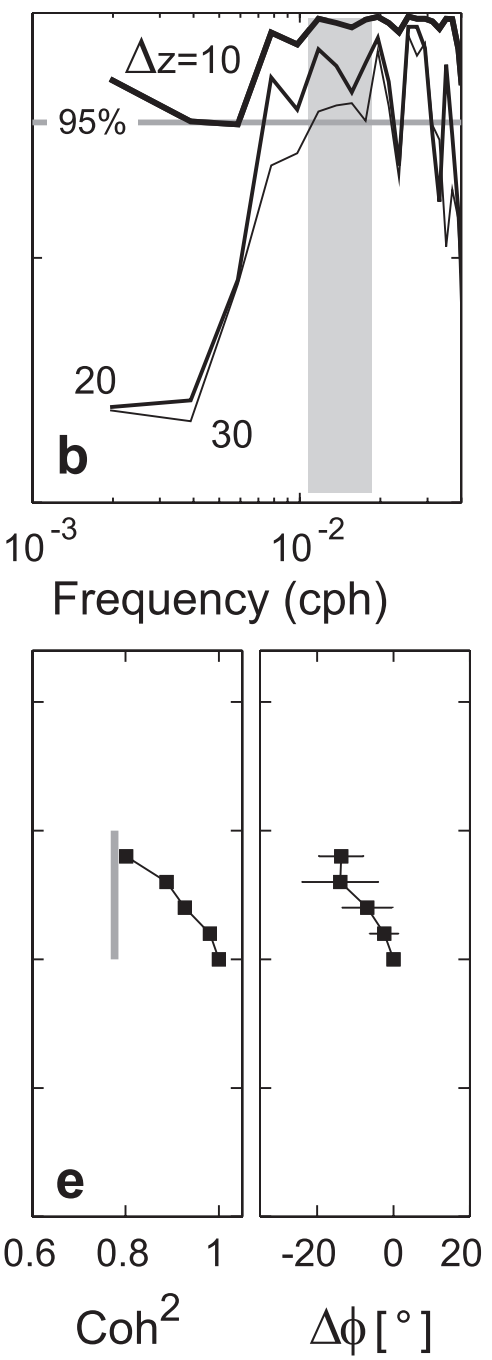

D3
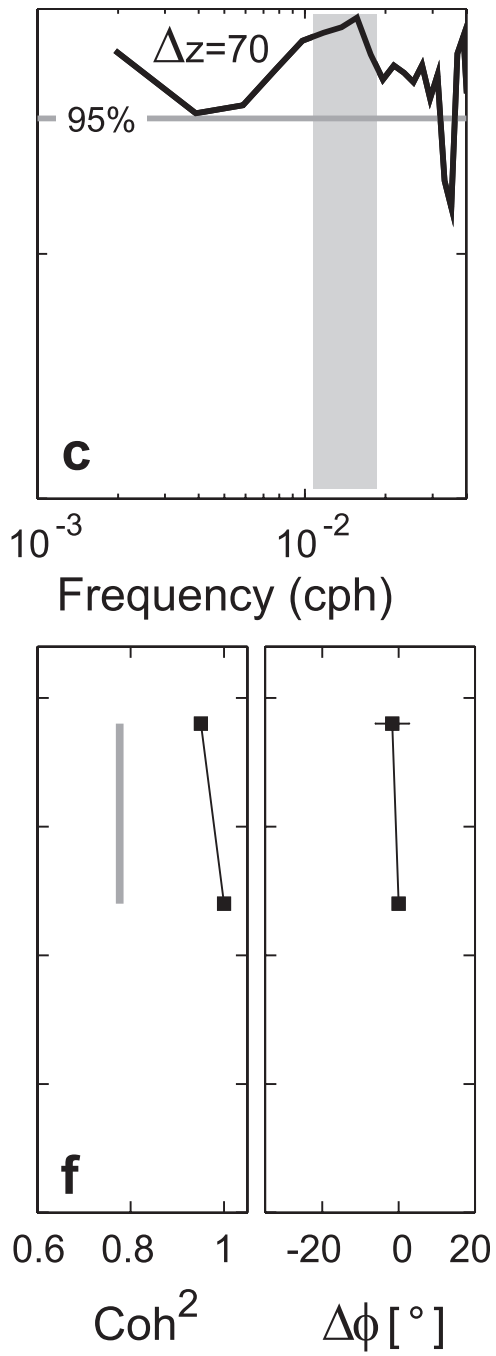

FIG. 11. (top) Coherence in the across-slope velocity $v$ for increasing vertical separation $\Delta z$ relative to a reference level, $z=100$ mab, at moorings (a) B2, (b) C2, and (c) D3. (bottom) Vertical profiles of band-averaged coherence and phase difference $\Delta \phi$ for (d) B2, (e) C2, and (f) D3. The $95 \%$ confidence level for the squared coherence is indicated by thin gray lines, and the frequency band of interest (corresponding roughly to periods of 2.5-5 days; see text) is marked by gray boxes in (a)-(c). Filled symbols (in this case all) mark that the average is significant at the $95 \%$ level. Positive $\Delta \phi$ indicates that the reference level, $z=100$ mab, leads.

indicating downward phase propagations (i.e., deeper instruments are lagging) of $0.28^{\circ} \pm 0.01^{\circ} \mathrm{m}^{-1}$ and $0.39^{\circ} \pm$ $0.06^{\circ} \mathrm{m}^{-1}$, respectively (the error estimate is the uncertainty derived from the misfit of the linear regression). This corresponds to downward phase speeds of 11$24 \mathrm{~m} \mathrm{~h}^{-1}$ and $9-17 \mathrm{~m} \mathrm{~h}^{-1}$, where the range reflects the width of the selected frequency band. The along-slope component $u$ gives similar results (not shown). At D3, keeping in mind that only two measurement levels are available, the phase in $v$ is nearly homogeneous over the extent of the mooring, whereas there is a downward phase propagation of $0.16^{\circ} \mathrm{m}^{-1}$ in $u$.
Using the records from $\mathrm{B} 2, \mathrm{C} 2$, and $\mathrm{D} 3$, the alongslope downstream structure is inferred. The analysis shows an along-slope westward propagation (in the negative $x$ direction) of the signal of $5^{\circ} \pm 0.6^{\circ} \mathrm{km}^{-1}$ and $3.3^{\circ} \pm$ $0.1^{\circ} \mathrm{km}^{-1}$ in $u$ and $v$, respectively, corresponding to a phase speed of $25-60 \mathrm{~cm} \mathrm{~s}^{-1}$. This is comparable to the along-slope propagation speed of $30 \mathrm{~cm} \mathrm{~s}^{-1}$ reported by Geyer et al. (2006). A phase speed of $25-60 \mathrm{~cm} \mathrm{~s}^{-1}$ and a period of about $T=3$ day gives a horizontal wavelength, $\lambda=c T$, on the order of $75-180 \mathrm{~km}$ along the slope, whereas the vertical wavelength is $800-1700 \mathrm{~m}$ for B2 and $650-1200 \mathrm{~m}$ for $\mathrm{C} 2$. The horizontal phase speed is 
comparable to the speed of an eddy propagating on a slope (Nof 1983),

$$
u_{\text {nof }}=\frac{g^{\prime} \tan s}{f}
$$

where $g^{\prime}=g \Delta \rho / \rho_{0}$ is the reduced gravity, $\Delta \rho$ is the density difference between the dense water and the ambient, $s$ is the bottom slope, and $f$ is the Coriolis parameter. In the study region, $g^{\prime} \approx 5 \times 10^{-3} \mathrm{~m} \mathrm{~s}^{-2}, f \approx 1.3 \times 10^{-4} \mathrm{~s}^{-1}$, and $s$ varies between 0.001 (D5) and 0.02 (D3) with a mean value of about 0.01 giving $u_{\text {nof }} \approx 50 \mathrm{~cm} \mathrm{~s}^{-1}$ (varying between 5 and $90 \mathrm{~cm} \mathrm{~s}^{-1}$ ).

Array D includes four moorings with current meters located at 100 mab, sufficiently above the frictional boundary layer to allow for analysis of the phase propagation in the across-slope direction. The propagation of the $u$ anomaly across array $\mathrm{D}$ is upslope (positive $y$ ) at a rate of $1.0^{\circ} \pm 0.4^{\circ} \mathrm{km}^{-1}$ or $0.8-1.4 \mathrm{~m} \mathrm{~s}^{-1}$ (Fig. 12). The signal in $v$ propagates in the opposite direction $\left(3.8^{\circ} \pm\right.$ $0.4^{\circ} \mathrm{km}^{-1}$ or $0.2-0.4 \mathrm{~m} \mathrm{~s}^{-1}$ ), causing the relative phase difference between $u$ and $v$ to increase from $30^{\circ}$ to $130^{\circ}$ across the array. The phase difference remains in the interval $0^{\circ}-180^{\circ}$ : that is, $u$ leads and the motion is CCW at D2-D5.

\section{h. Transport}

The mesoscale oscillations have a distinct signature in volume transport. The transport of water colder than a given isotherm past the mooring arrays was estimated by summing up the contribution from the individual moorings $Q_{i}$ given by

$$
Q_{i}=\sum_{z=1}^{z=z_{0}} u^{*}(z) L \Delta z,
$$

where $u^{*}$ is the velocity component perpendicular to the section, $z_{0}$ is the height above bottom of the isotherm (or the height of the uppermost temperature measurement if the limiting isotherm is above the mooring), $L$ is the representative width of the mooring, and $\Delta z=1 \mathrm{~m}$. Here, $L$ is taken to be the mean distance to the neighboring moorings or half the distance to the next mooring $+5 \mathrm{~km}$ for the edge moorings. The values of $L$ are listed in Table 1 . The lowermost temperature record, which is typically in the bottom mixed layer, is extrapolated to the bottom, whereas the lowermost velocity is assumed to decrease linearly to zero at the bottom. At times when the velocity measurements do not reach the height of the limiting isotherm, the uppermost velocity record is extrapolated upward.

The transport of water colder than $3^{\circ} \mathrm{C}$ past the arrays is shown in Fig. 13a. Figures 13b,c show the transport at

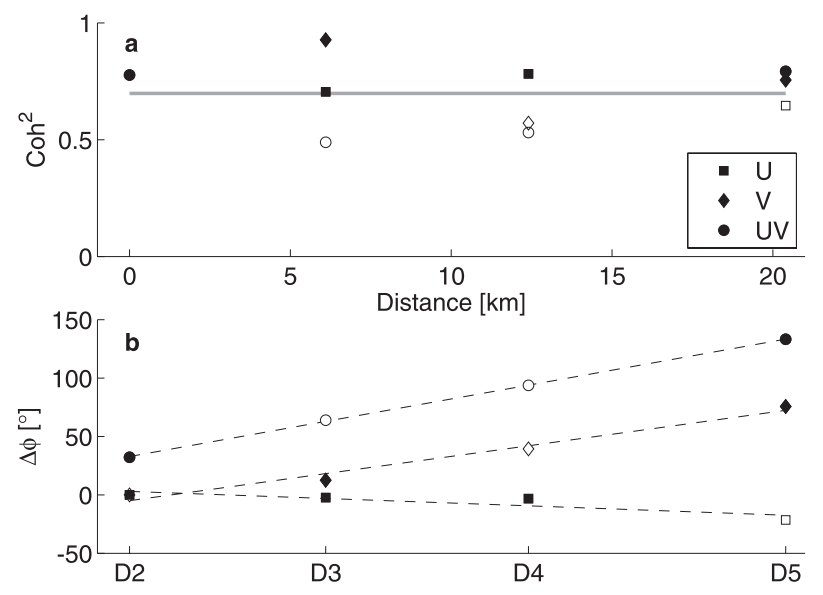

FIG. 12. (a) Coherence and (b) phase difference $(\Delta \phi)$ in (i) the along-slope $u$ and across-slope $v$ velocity at 100 mab for increasing horizontal separation relative to mooring D2 (i.e., between D3 and D2, D4 and D2 and D5 and D2) and (ii) between the velocity components ( $u$ and $v$ ) at each mooring. Positive $\Delta \phi$ indicates that D2 (for first group) and $u$ (for second group) lead. Filled symbols in (b) mark that the result is significant at $95 \%$ level, indicated with a gray line in (a).

arrays B and D below various isotherms. The transport varies between zero and $2.1 \mathrm{~Sv}$, and the cold water arrives and flows past the mooring arrays in "bulges" corresponding to the oscillations discussed above. The bulges travel along the slope using about 1-1.5 days to cover the $60 \mathrm{~km}$ between $\mathrm{B}$ and $\mathrm{D}$ arrays, whereas it travels the $30 \mathrm{~km}$ between $\mathrm{C}$ and $\mathrm{D}$ in 0.5 days. This corresponds to a propagation speed of $50-70 \mathrm{~cm} \mathrm{~s}^{-1}$, which is in the upper range of the estimated along-slope phase velocity (section $3 \mathrm{~g}$ ).

The mean transport of water colder than $3^{\circ} \mathrm{C}$ is $1 \mathrm{~Sv}$ at $\mathrm{B}$ and $0.7 \mathrm{~Sv}$ at $\mathrm{C}$ and D. This is less than the 10-yr average of $1.7 \mathrm{~Sv}$ (dashed lines in Fig. 13b) measured at the sill (Hansen and Østerhus 2007), which consists mainly of water colder than $0^{\circ} \mathrm{C}$. The $3^{\circ} \mathrm{C}$ isotherm is typically within the mooring range for more than $95 \%$ of the time for all moorings except for the edge moorings D1 (85\%) and D5 (20\%). During the large transport peaks in June, the volume flux at array B resembles the mean situation at the sill (note that there is no mean estimate for water colder than $-0.25^{\circ} \mathrm{C}$ at the sill). The earlier, smaller peaks consist mainly of warmer water and notably water colder than $-0.25^{\circ} \mathrm{C}$ : that is, the Faroe Shetland Channel Bottom Water (FSCBW) or the density range 5 of Mauritzen et al. (2005) is absent. By array D, the overflow plume has entrained and mixed with warmer, ambient water and there is generally no water colder than $0^{\circ} \mathrm{C}$ left (Fig. 13c). Meanwhile, the total transport of water colder than $3^{\circ} \mathrm{C}$ has decreased. This is not an artifact of undersampling but the result of entrainment 

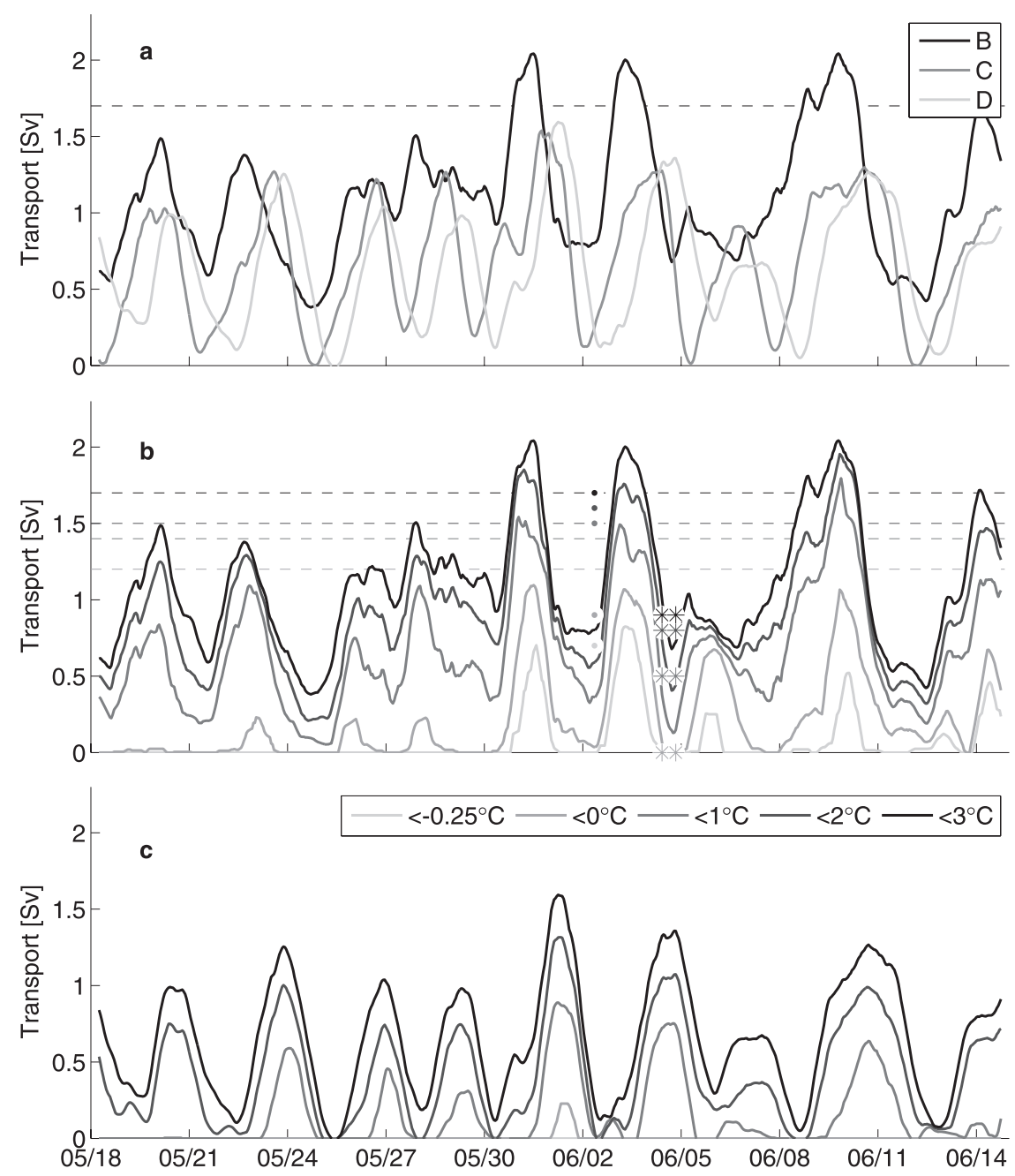

FIG. 13. (a) Transport of water colder than $3^{\circ} \mathrm{C}$ past the mooring arrays $\mathrm{B}, \mathrm{C}$, and $\mathrm{D}$ as a function of time. The dashed line shows the mean transport (1995-2005) of water colder than $3^{\circ} \mathrm{C}$ across the sill (Hansen and Østerhus 2007). Volume transport of water colder than a specified temperature for mooring (b) B and (c) D. Dashed lines indicate the mean transport across the sill in the same classes (Hansen and Østerhus 2007). Note that no mean value for water colder than $-0.25^{\circ} \mathrm{C}$ (FSCBW or range 5 in Mauritzen et al. 2005) is available at the sill. The legend in (c) is valid also for (b). The dots and stars in (b) indicate the transport estimated from LADCP/CTD sections (Fer et al. 2010) obtained across the sill and in the vicinity of array $\mathrm{B}$, respectively, where their position on the time axis show the time of occupation of the section. The estimates from the sill have been moved forward in time assuming a velocity of $35 \mathrm{~cm} \mathrm{~s}^{-1}$ (the mean velocity of B1 and B2) covering the $55 \mathrm{~km}$ between the sill and array B.

and mixing, causing a shift of the transport toward higher temperature classes, which unfortunately are not captured satisfactorily by the short moorings.

The transport estimates include errors due to error in $L$, extrapolation and linearization between instruments, failing to capture the plume core (observed to be relatively narrow in Fig. 2a), and instrument measurement errors where the latter is expected to be relatively small. Extending the unresolved integration area from 5 to $10 \mathrm{~km}$ on the flanks increases the transport estimates by a maximum of $20 \%$. Giving more weight on the central mooring, by increasing its representative width by $5 \mathrm{~km}$ on either side, leads to an increase of $40 \%$. All together, the uncertainty in transport calculations is estimated to be $50 \%$. The transport estimates based on the LADCP/ CTD sections (Fer et al. 2010) occupied across the sill and in the vicinity of array B on 31 May and 4 June, respectively, agree reasonably well with the estimate from the moorings during the same time period (Fig. $13 \mathrm{~b})$, lending confidence on the method. 


\section{i. Variability in oscillation period}

Based on data from 25 moorings divided on three deployments, Geyer et al. (2006) describe the oscillation in the region as being "highly regular" with a period of $88 \mathrm{~h}$. The oscillations described here are less regular, and $88 \mathrm{~h}$ does not stand out as the preferred period. The limited length of the present time series (giving low spectral resolution at the low frequencies of interest) and variations in the dominant frequency identified with wavelet analysis (not shown) make the Fourier analysis unsuitable to determine the oscillation period accurately. Instead, the mean period over four moving consecutive peaks identified in $u, v$, and $T$ (Fig. 3) were used to estimate a time series of the oscillation period. The results are shown for the moorings at the slope, excluding B3, D1, and D5 (Fig. 14). A sudden transition is apparent in early June when a uniform and relatively constant oscillation period of $69 \pm 6 \mathrm{~h}$ becomes, at least for $u$ and $v$, more chaotic with periods varying, in time and space, between 2.5 and 5 days. In the latter part of the record, no relation between mooring location (i.e., distance from sill or mooring depth) and period is discernible.

During the period with uniform oscillation across the slope (i.e., the second half of May), the coldest water mass (FSCBW) is not observed at array B, whereas it is observed regularly in the rest of the record. This suggests either the lack of FSCBW overflow at the sill at this time or that the mixing is stronger, diluting the FSCBW overflow plume to a lighter water mass by array $\mathrm{B}$. The lack of cold overflow could be either a cause of the uniform oscillation or an effect, if the oscillation is generated farther upstream. Concurrent temperature data from the World Ocean Circulation Experiment (WOCE) mooring in the sill region at 573-m depth (position marked by a dot in Fig. 1) show variable bottom temperature with an apparent mean of about $3.5^{\circ} \mathrm{C}$ (see Mortensen et al. 2009, p. 31) but no striking change in temperature before/after 1 June. However, this mooring is on the northeastern flank of the channel, and it does not capture the coldest part of the outflow. Mooring A, deployed on 30 May, shows a gradual decrease in the overflow speed followed by an abrupt increase on 2 June from 85 to $150 \mathrm{~cm} \mathrm{~s}^{-1}$ within $12 \mathrm{~h}$, consistent in all bins between 777- and 811-m depths, but with a weaker peak below $795 \mathrm{~m}$ (in low-passfiltered $1-\mathrm{h}$ and depth-averaged series, this is an increase from about 100 to $127 \mathrm{~cm} \mathrm{~s}^{-1}$; Fig. 9). This is the highest velocity sampled during the one-month-long record. Already at the sill crest, mooring A shows pronounced oscillations in the 2.5-5-day period in the all three velocity components in the sampled range within 70 mab. The cold overflow is persistent and never reverses. The
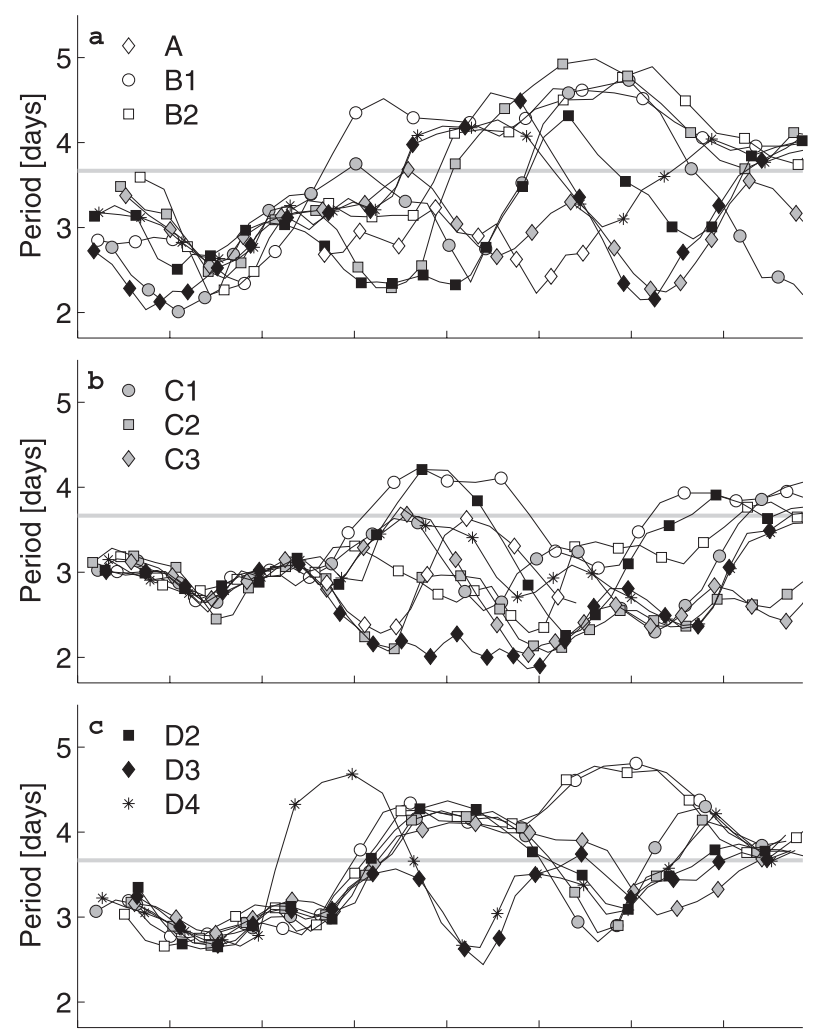



FIG. 14. Oscillation periods obtained from the located peaks in (a) $u$, (b) $v$, and (c) $T$. The gray line marks the 88 -h period found by Geyer et al. (2006).

strengths of the fluctuations are significant but less than the mean flow. Our data thus suggest that the oscillations are not simply generated downstream of the sill crest.

\section{Discussion}

The data presented in section 3 show subinertial, nontidal energetic oscillations in velocity and temperature records with a period of 2.5-5 days. Similar oscillations have been reported previously in the region: for example, by Geyer et al. (2006), who observed a highly regular oscillation with a period of $88 \pm 4 \mathrm{~h}$ in nearbottom (within $30 \mathrm{~m}$ ) velocity and temperature records. The enhanced sea level variability observed downstream of the sill (Høyer and Quadfasel 2001) suggests that the oscillations are associated with eddies influencing the sea surface height.

Our data show a significant positive correlation between vorticity and temperature at the $\mathrm{C}$ and $\mathrm{D}$ arrays (Fig. 10), suggesting a train of alternating cold-core anticyclonic and warm-core cyclonic eddies. This pattern agrees with the observed convergent and divergent 
a

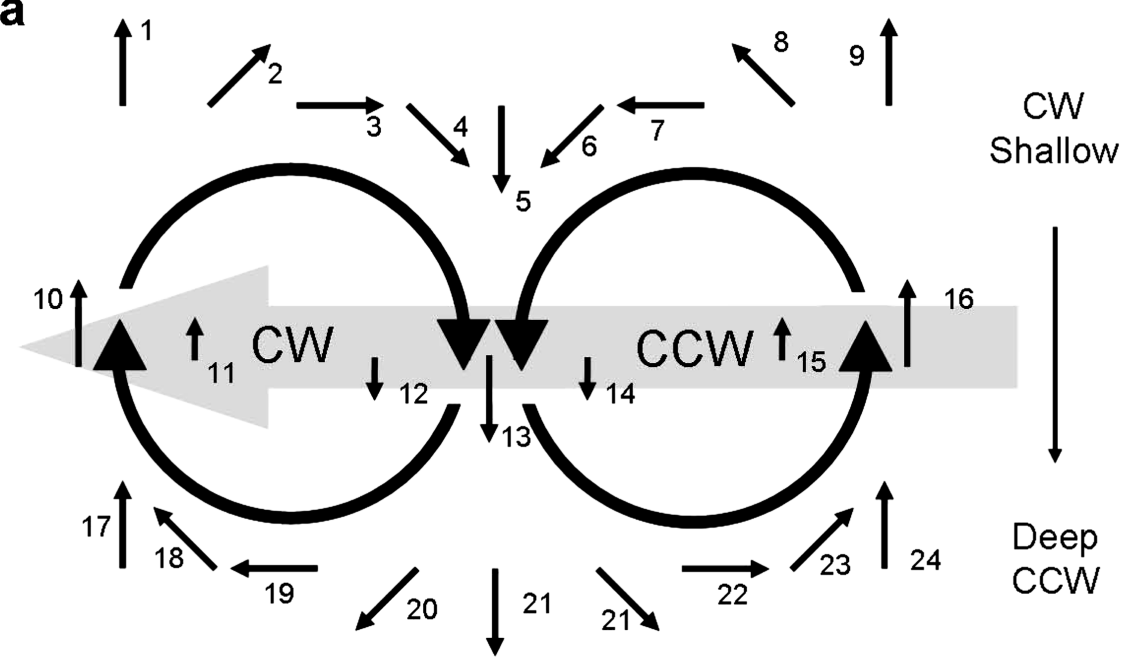

b

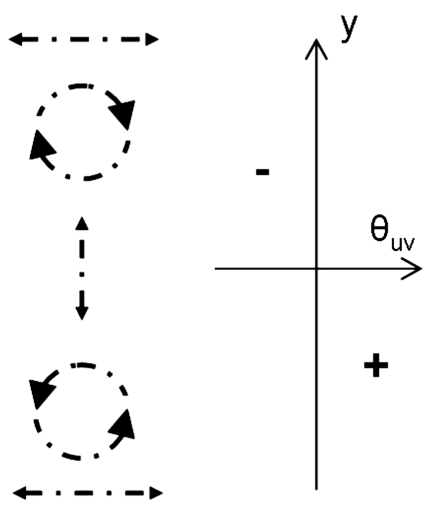

FIG. 15. (a) Sketch of a cyclonic and an anticyclonic eddy translating toward the left on a slope, causing a local CW motion on the upper part of the slope, a CCW motion on the lower part, and a rectilinear oscillation across the slope in the center. The gray arrow indicates the direction of eddy translation; the thick black arrows indicate the rotation of the eddy; and the small, numerated black arrows indicate the current anomalies registered at moorings located on the shallow side (arrows 1-9), in the center (arrows 10-16), and on the deep side (arrows 17-25) of the eddies. (b) Current ellipses at moorings across the slope. (c) Sign of phase difference $(U-V)$ across the slope.

current vectors representative of $\mathrm{CCW}$ and $\mathrm{CW}$ eddies (Foldvik et al. 1988) during periods with high and low temperatures, respectively. The observed distribution of $\mathrm{CW}$ and $\mathrm{CCW}$ rotation and temperature across the slope, however, is not supportive of the train of alternating eddies with warm and cold cores. Eddies translating along a slope with shallow water on the right (Northern Hemisphere) will be registered as CW motion on moorings located on the shallow side of the eddy center, whereas a mooring located on the deep side will register CCW motion. A mooring in the center of the eddy will detect rectilinear motion perpendicular to the slope (Fig. 15). This is true regardless of whether the eddy is cyclonic or anticyclonic. The rotation of the velocity vector at a single mooring hence reveals its location on the slope relative to the eddy center and not the sense of rotation of the eddy. As evidenced by Fig. 4, the deeper moorings of array $\mathrm{C}(\mathrm{C} 2$ and $\mathrm{C} 3)$ generally show a $\mathrm{CCW}$ motion, whereas the flow at $\mathrm{C} 1$ is rectilinear and perpendicular to the mean current. This suggests that the mooring array covers only the deeper part of the eddy whose center is located in the vicinity of $\mathrm{C} 1$. The cold core is hence not located in the eddy center, because observations show longer, thicker, and colder episodes of plume water at $\mathrm{C} 2$ than at $\mathrm{C} 1$ (i.e., farther down the slope). Analogously, the results of the coherence-phase analysis from array D show CCW motion at D2-D5 with the phase difference decreasing toward shallow water (Fig. 12). This rectilinear motion indicates the passage of an eddy center farther upslope. This is supported by the transition of $\mathrm{EKE}^{*}$ at the $\mathrm{C}$ and $\mathrm{D}$ arrays from across-slope component at shallow moorings to alongslope component at deeper moorings (Fig. 6b). The cold core, or the majority of the cold water, however, passes across the moorings D2 and D3, downslope from the eddy center. D1 does not detect cold water. The relatively shallow B1 and B2 moorings mainly show CW motion (Fig. 7), in agreement with a location upslope of the eddy center. The shift in EKE*, however, resembles that in arrays $\mathrm{C}$ and $\mathrm{D}$, contrary to what would be expected. This is partly biased by results from B1, which is situated near a relatively sharp bend in the topography (see Fig. 1), where the mean current is not aligned with the local isobath used to define the coordinate system (Fig. 8).

We conclude that the scale of the eddies in the acrossslope direction is larger than the extent of the cold bulges and that the bulges are not located in the eddy center (i.e., the cold eddies are not rotating around a cold core). This feature is not recognized in modeled eddies. In studies where the characteristics of the eddies are described, the cold core and the rotation center coincide (Spall and Price 1998; Käse et al. 2003).

\section{a. Generation mechanisms}

Eddies develop in modeled overflows, both in laboratory (Smith 1977; Lane-Serff and Baines 1998; Cenedese et al. 2004) and numerically (Jiang and Garwood 1996; Ezer 2006; Seim et al. 2010). Their generation is generally suggested to be due to vortex stretching (Lane-Serff and Baines 1998; Spall and Price 1998), baroclinic instability 
(Smith 1976; Swaters 1991), or changes in topography (Nof et al. 2002; Pratt et al. 2008). These mechanisms are discussed below.

\section{1) VorteX STRETCHING}

Vortex stretching is expected to generate strong, cyclonic eddies in the overlying, ambient water as the water column conserves the potential vorticity while being stretched (Lane-Serff and Baines 1998). The cyclonic eddies are associated with a negative sea surface height (SSH) anomaly and they "collect" dense water in domes below them. The cyclonic rotation in the lower layer is weaker or even anticyclonic. Idealized numerical simulations (Ezer 2006) show eddies about 100-200 km downstream of the FBC sill, with significant, negative SSH anomalies of about 10-15 cm. Maps of SSH anomaly for the period covering the mooring deployment duration (not shown) derived from altimeter products produced by Ssalto/Duacs and distributed by Archiving, Validation, and Interpretation of Satellite Oceanographic data (AVISO; http://www.aviso.oceanobs.com/duacs/) show no discernible signature of cyclones. A scaling proposed by LaneSerff and Baines (1998) suggests that eddies generated through vortex stretching in the FBC overflow have a period of about 3-5 days and a radius on the order of $10 \mathrm{~km}$ and propagate along the slope at a speed of 5$8 \mathrm{~cm} \mathrm{~s}^{-1}$. Although the periodicity agrees well with the observations, the length scale, the translation speed, and the vertical organization of the flow do not; the latter, however, is not resolved properly in our observations. Taken together with the lack of negative SSH anomalies at the site, we conclude that vortex stretching is not the dominant mechanism responsible for the observed mesoscale variability.

\section{2) BAROCLINIC INSTABILITY}

Baroclinic instabilities can form in stratified, rotating fluid where the isopycnals are sloping, giving rise to a geostrophic flow in thermal wind balance. Under favorable conditions, a small perturbation may tap the available potential energy (by reducing the slope of the isopycnal surfaces) and grow, forming a train of alternating cyclonic and anticyclonic eddies. In a geostrophically balanced overflow plume in the Northern Hemisphere, a baroclinic instability must induce a net buoyancy flux to the left of the current (looking downstream) to release energy and grow. In FBC, where density is determined by temperature, a buoyancy flux to the right is equivalent to a heat flux directed to the right of the current (downgradient lateral heat flux). In agreement with the theory, all moorings, with the exemption of D2, show a heat flux to the right of the mean current (Fig. 8). Note, however, that only horizontally divergent heat fluxes are related to baroclinic conversion events (Cronin and Watts 1996). Unfortunately, it is not possible, using the present dataset, to identify an upper-isotherm boundary or the lateral gradients needed to calculate the divergence of the temperature flux following Voet and Quadfasel (2010).

Swaters (1991) describes a type of baroclinic instability for the downslope side of the plume where the isopycnals tend to slope steeper than the bottom. This mechanism is expected to generate the strongest variability on the deep side of the overflow and within the dense layer. The period of the most unstable wave in Swaters's model (using values representative of the FBC) is 33 days. Because this period is much longer than the observed period of the mesoscale oscillations, we rule out the baroclinic instability on the downslope side of the plume.

Smith (1976) develops a quasigeostrophic two-layer model to analyze the stability of baroclinic flow in a sloping channel of constant width. When applied to the DSO, the properties of the most unstable wave in the model agreed well with observations. Using parameters representative for the FBC (upper- and lower-layer thicknesses and velocities of 650 and $150 \mathrm{~m}$ and 0 and $60 \mathrm{~cm} \mathrm{~s}^{-1}$, respectively; channel width of $50 \mathrm{~km}$; density anomaly of $0.4 \mathrm{~kg} \mathrm{~m}^{-3}$; and a bottom slope of 0.01 ), the model yields the most unstable waves with a wavelength of $100-120 \mathrm{~km}$ and a period of 3.3-3.8 days. Here, the narrower channel and the thicker upper layer are the most noticeable differences compared with the DSO. It is questionable to what the degree the results of the model are applicable in FBC, which rapidly widens downstream of the sill and violates the model assumption of narrow channel (compared to the Rossby radius). The partition of the EKE* between $u$ and $v$ components across the slope (Fig. 6b) disagrees with the predictions from Smith's model (see his Fig. 9), where the majority of the EKE* is found in the $v$ component. Nevertheless, the results agree remarkably well with the observed period and the length scale of the oscillations. However, as pointed out by Spall and Price (1998), the time and length scales in any timedependent model including stratification and a sloping bottom are likely to be related to the Rossby wave dispersion relation and hence are not unique for the baroclinic instability. Gill et al. (1974) discuss means to distinguish baroclinic unstable disturbances from baroclinic Rossby waves, which have similar propagation velocity and vertical structure. One main difference is that, in a baroclinic instability the phase changes with depth and there is an upward phase propagation (Pedlosky 2003). Our results indicate a downward phase velocity. This, together with the observation that the mean slope of the isotherms tends to parallel the bottom (Fig. 6), a configuration that is stable 
with respect to baroclinic instabilities (Phillips 1954; Pavec et al. 2005), suggests that baroclinic instability can be discarded as the origin of the oscillations.

\section{3) BotTOM SLOPE}

Nof et al. (2002) show that a gently sloping bottom may fail to support a continuous, inviscid plume because, for a shallow enough slope, the interface slope on the upslope side of the plume would induce an unphysical, upstream flow. If the bottom slope is less than a critical slope, $S_{c}=\alpha f \sqrt{H / g^{\prime}}$, the plume can only exist as a train of anticyclonic eddies. Here, $H$ is the maximum plume thickness, and $\alpha$ is a coefficient of order unity whose value depends on the potential vorticity of the plume. Using representative values for the $\mathrm{FBC}\left(f=1.3 \times 10^{-4}\right.$, $H=200 \mathrm{~m}, g^{\prime}=5 \times 10^{-3} \mathrm{~m} \mathrm{~s}^{-2}$, and $\alpha=1$ ), we obtain $S_{c} \approx 0.02$ or larger. The mean slope in the area is 0.01 , and a substantial part of the slope in the outflow region is subcritical (marked in Fig. 2). According to the theory, the plume is hence expected to break up into anticyclonic eddies, whereas observations show both cyclonic and anticyclonic eddies. Friction is found to be important in the turbulent FBC overflow dynamics (Fer et al. 2010; Seim and Fer 2011), and it is questionable to what degree an inviscid theory is applicable. Friction and Ekman dynamics tend to flatten out the interface on the upslope side of the plume (Wåhlin and Walin 2001) and effectively remove the cause of the unphysical, upstream flow.

\section{b. Oscillations at the sill}

The theories above describe instabilities generated once the plume is flowing on the slope, (i.e., downstream of the sill). However, low-frequency mesoscale oscillations are observed already in the sill region. Our data from mooring A, located on the southwestern flank of the channel slightly upstream of the sill, do show oscillations (Fig. 9). Data collected simultaneously at the WOCE mooring (Fig. 1), located at the other flank of the channel, also show prominent oscillations at comparable periods (S. Østerhus 2010, personal communication). Saunders (1990) describes a seiche-like oscillation at the sill with a period of 3-6 days, which he concludes is not a standing wave on the interface (which would have a period of about 0.5 days), Kelvin waves, bottom-trapped waves, or baroclinic instabilities. Oscillations at the sill region are mentioned elsewhere (Geyer et al. 2006; Hansen and Østerhus 2007), and periodic fluctuations of the overflow at the sill are observed in the regional model by Seim et al. (2010) (see the variability in transport in their Fig. 3b). Observations from various sources indicate that the 3-6-day-period oscillations near the sill crest are typical and not exceptional. The presence of oscillations already at the sill region suggests a generation mechanism different from the one at play in overflows where eddies develop downstream of the sill, notably the Denmark Strait (Smith 1976; Bruce 1995) and the Filchner Overflow (Darelius et al. 2009) as well as most laboratory experiments (e.g., Smith 1977; Cenedese et al. 2004; Wåhlin et al. 2008).

\section{c. Topographic Rossby waves}

The configuration with dense water on a slope is in many ways similar to a two-layer fluid on a $\beta$ plane, where the change in water depth due to the sloping bottom plays the role of $\beta$. The slope can hence support topographic Rossby waves (TRW; Rhines 1970), which in the two-layer case can be barotropic, baroclinic, or bottom-trapped depending on the ratio between the wavelength and the baroclinic Rossby radius and on stratification. The restoring force of the wave results from the change of vorticity as the water column crossing the isobaths is stretched or squeezed.

Rhines (1970) shows that, in the presence of stratification $N$ and significant bottom slope $s$, the structure of the low-frequency motions is bottom intensified with a bottom trapping scale of $f / N K_{H}$, where $K_{H}=\left(k^{2}+l^{2}\right)^{1 / 2}$ is the horizontal wavenumber with along-slope $k$ and across-slope $l$ components. The buoyancy frequency, inferred from SBE CTD measurements of the 2008 survey, when averaged in $10-\mathrm{m}$ bins of height above bottom vary between 1.5 and $4 \times 10^{-3} \mathrm{~s}^{-1}$ in the bottom $400 \mathrm{~m}$, with an average of about $N=3 \times 10^{-3} \mathrm{~s}^{-1}$. Typical horizontal wavelength $\lambda=2 \pi / K_{H}$ of $100 \mathrm{~km}$ and $N=3 \times 10^{-3} \mathrm{~s}^{-1}$ lead to a trapping scale of about $700 \mathrm{~m}$, comparable to the water depth. The dispersion relation is given by $\omega=s N \sin \theta$, provided that the slope parameter $s / K_{H} H$ is small and $\tanh \left(N K_{H} H / f\right) \sim 1$ : that is, the short-wave/large stratification limit applies. Here $H$ is the water depth and $\theta$ is the orientation angle of the wavenumber vector from downslope. Using $H=1000 \mathrm{~m}$ gives $s / K_{H} H=0.16$ and $\tanh \left(N K_{H} H / f\right)=0.9$, and the simplified dispersion relation can be used with confidence. According to the dispersion relation, the transverse motions of waves change from along-slope orientation for low frequency to a cross-slope orientation at higher frequencies (Pickart and Watts 1990). The shortest period (highest frequency) achievable is thus $2 \pi / s N=2.4$ days using a bottom slope of $s=0.01$ and the average $N$. The expected period of TRW varies between 2 and 5 days for the given range of $N$, in excellent agreement with the observations. This is again comparable to the prediction by Smith's (1976) model because the time and length scales of baroclinic instability are similar to the Rossby waves.

If TRW were the chief source of observed mesoscale perturbation, the PA associated with the oscillations 
would align with the constant phase lines (i.e., normal to the wavenumber vector and the phase velocity). The phase velocity always has a component along the isobaths with shallow water to the right in the Northern Hemisphere (i.e., PA is rotated clockwise from isobaths by the angle $\theta$ described above). Another observational signature is the turning of PA to a more cross-isobath orientation at higher frequencies. The orientation of PA for the 2.5-5-day-period oscillations together with the local isobaths are shown in Fig. 8. Especially at B1 and at upper instruments in central D moorings, the characteristic clockwise tilt of PA from the isobaths can be seen. The orientations of the isobaths are inferred at $10-\mathrm{km}$ scale. The isobath orientation that will be felt by TRW should be inferred at the horizontal wave scale on the order of $100 \mathrm{~km}$. The direction of the isobaths in our study region is very irregular and does not allow for an accurate estimate of the dynamical significance of the topography. To detect the expected change in orientation of PA, the analysis in section $3 \mathrm{c}$ is repeated for the frequency bands corresponding to 3.5-4.2-, 10.7-, and 21-day periods. At B1, the PA orientation inferred at 60-100 mab increases from $110^{\circ}-140^{\circ}$ (21 days) to $115^{\circ}-$ $150^{\circ}$ (10.7 days) and $145-180^{\circ}$ (3.5-4.2 days). Assuming a large-scale isobath orientation of $110^{\circ}$ from north, these correspond to $\theta=0^{\circ}-30^{\circ}, 5^{\circ}-40^{\circ}$, and $35^{\circ}-70^{\circ}$, consistent with the theoretical prediction of $\theta=7^{\circ}, 13^{\circ}$, and $35^{\circ}-44^{\circ}$, respectively, using $s=0.01$ and the average $N$. At C2, at 80-120 mab, a similar pattern is observed. Not all moorings, however, conform to the theory. Similar inconsistent relative inclination of PA has been inferred at other sites where energetic TRW were conclusively observed (Johns and Watts 1986; Pickart and Watts 1990). Phase propagation inferred from coherence-phase analysis (section $3 \mathrm{~g}$ ) have westward (for both $u$ and $v$ ) alongslope and downslope (for $v$ component along array D) components consistent with TRW.

Strong bottom friction will lead to a decay in the wave energy. The spindown time for a barotropic Rossby wave in water depth $H$ is $T_{s}=H /\left(2 A_{z} f\right)^{1 / 2}$, where $A_{z}$ is the vertical eddy viscosity. Assuming an eddy viscosity comparable to the measured eddy diffusivity of $10^{-2}$ to $10^{-1} \mathrm{~m}^{2} \mathrm{~s}^{-1}$ in the bottom $50 \mathrm{~m}$ (Fer et al. 2010), decay time is 7 days using $H=1000 \mathrm{~m}$ and $A_{z}=10^{-2} \mathrm{~m}^{2} \mathrm{~s}^{-1}$. Using the trapping length scale instead of water depth or the overflow plume thickness reduces the decay time to 3-5 days. For a spindown time of 5 days and a phase velocity of $40-80 \mathrm{~cm} \mathrm{~s}^{-1}$, the waves will travel a distance of about $170-350 \mathrm{~km}$, hence our mooring arrays will capture the waves before they decay. Høyer and Quadfasel (2001) report the maximum SSH variability about $30 \mathrm{~km}$ downstream of sill, with no detectable signature $160 \mathrm{~km}$ downstream (i.e., 3 days or roughly one wavelength), consistent with our calculations. Overall, we conclude that the characteristics of the mesoscale oscillations apparent in our dataset are broadly consistent with TRW.

The generation mechanism for TRW needs further studies. We hypothesize that perturbations upstream of the sill, in the Faroe-Shetland Channel, associated with meanders and eddies of the warm Atlantic Water inflow can be a source for these waves. Sherwin et al. (2006) report, from several sources of observations, that the frontal region between Shetland and the Faroe Islands homes an unstable flow forming large-scale meanders. On the continental slope off of Cape Hatteras, energetic TRW were reported, associated with eastward propagating meanders of the Gulf Stream (Johns and Watts 1986; Pickart and Watts 1990; Pickart 1995). The waves can also be excited by local or remote atmospheric forcing (Gordon and Huthnance 1987). Using a ray tracing model, Pickart (1995) identified the source region for the energy radiation. A similar analysis will help clarify the source of TRW observed in FBC.

\section{d. Role in mixing}

However generated, the eddies are expected to influence mixing and hence the final properties of the plume water. Numerical work shows that eddies influence the descent rate of plume water (Tanaka 2006; Seim et al. 2010) and that the dissipation rate of turbulent kinetic energy, which can be related to the vertical mixing, may change with a factor of 2-10 as an eddy passes (Seim et al. 2010). The latter is supported by the observations presented here, as the Richardson number oscillates between critical and noncritical values (Fig. 7): that is, between shear/stratification profiles that allow and suppress shear-induced turbulence and vertical mixing. In addition to vertical mixing, eddies cause horizontal stirring, leading to lateral heat fluxes and entrainment (Voet and Quadfasel 2010; Quadfasel and Käse 2007).

\section{Concluding remarks}

Mesoscale oscillations with periods of 2.5-5 days in velocity and temperature are observed to dominate the 2-month-long mooring records from the Faroe Bank Channel overflow plume. The variability is large, and any results (e.g., transport estimates, mixing etc.) based on single CTD and LADCP sections must be considered as snapshots only that may bear little or no relation to the mean situation. Measurements of water properties or mixing should preferably cover at least one oscillation period. 
The data show a train of alternating warm and cyclonic eddies and cold and anticyclonic eddies moving past the moorings with shallow water to their right. The eddies are associated with 100-200-m-thick boluses of cold water, but the core of the eddies do not coincide with the maximum in plume thickness, which is located farther down the slope. The horizontal phase velocity suggests a length scale in the along-slope direction of about $75-180 \mathrm{~km}$.

We find the existing theories on eddy generation in dense overflows, notably vortex stretching and baroclinic instabilities, partly or entirely inconsistent with our observations. The presence of oscillations already at the sill region suggests a generation mechanism different from the one at play in overflows where eddies develop downstream of the sill. The characteristics of the mesoscale oscillations apparent in our dataset are broadly consistent with topographic Rossby waves.

Further field studies, accompanied by theoretical and numerical studies, are needed to understand how the oscillations are generated and how they impact mixing and entrainment. Future moorings and field experiments should preferably be designed to cover not only the plume path but also the shallower part of the slope, because the results presented here suggest that the "plume moorings" capture only the lower part of the eddies. They should also aim to cover a larger part of the water column, to explore the behavior of the upper layer.

Acknowledgments. This study is funded by the Research Council of Norway through Bipolar Atlantic Thermohaline Circulation (BIAC). Comments and suggestions from Prof. P. Rhines and two anonymous reviewers were greatly appreciated. The authors are grateful to Gunnar Voet, who prepared the array D data, and crew and scientists involved in the deployment and recovery of the moorings.

\section{REFERENCES}

Borenäs, K., and P. Lundberg, 2004: The Faroe-Bank Channel deep-water overflow. Deep-Sea Res. II, 51, 335-350.

Bruce, J. G., 1995: Eddies southwest of the Denmark Strait. DeepSea Res. I, 42, 13-29.

Cenedese, C., J. A. Whitehead, T. A. Ascarelli, and M. Ohiwa, 2004: A dense current flowing down a sloping bottom in a rotating fluid. J. Phys. Oceanogr., 34, 188-203.

Cronin, M., and D. R. Watts, 1996: Eddy-mean flow interaction in the Gulf Stream at $68^{\circ} \mathrm{W}$. Part I: Eddy energetics. J. Phys. Oceanogr., 26, 2107-2131.

Darelius, E., L. H. Smedsrud, S. Østerhus, A. Foldvik, and T. Gammelsrød, 2009: Structure and variability of the Filchner overflow plume. Tellus, 61A, 446-464.
Dewey, R., 1999: Mooring Design \& Dynamics-A Matlab package for designing and analyzing oceanographic moorings. Mar. Models, 1, 103-157.

Dickson, R., and J. Brown, 1994: The production of North Atlantic Deep Water, sources, rates, and pathways. J. Geophys. Res., 99, 12 319-12 341.

Ezer, T., 2006: Topographic influence on overflow dynamics: Idealized numerical simulations and the Faroe Bank Channel overflow. J. Geophys. Res., 111, C02002, doi:10.1029/2005JC003195.

Fer, I., G. Voet, K. S. Seim, B. Rudels, and K. Latarius, 2010: Intense mixing of the Faroe Bank Channel overflow. Geophys. Res. Lett., 37, L02604, doi:10.1029/2009GL041.

Foldvik, A., K. Aagaard, and T. Torresen, 1988: On the velocityfield of the East Greenland Current. Deep-Sea Res., 35 (8).

GEBCO, 2003: Centenary Edition of the GEBCO Digital Atlas. Intergovernmental Oceanographic Commission and the International Hydrographic Organization, CD-ROM.

Geyer, F., S. Østerhus, B. Hansen, and D. Quadfasel, 2006: Observations of highly regular oscillations in the overflow plume downstream of the Faroe Bank Channel. J. Geophys. Res., 111, C12020, doi:10.1029/2006JC003693.

Gill, A. E., J. S. A. Green, and A. J. Simmons, 1974: Energy partition in large-scale ocean circulation and production of midocean eddies. Deep-Sea Res., 21, 499-528.

Gordon, R. L., and J. M. Huthnance, 1987: Storm-driven continental shelf waves over the Scottish continental shelf. Cont. Shelf Res., 7, 1015-1048.

Hansen, B., and S. Østerhus, 2000: North Atlantic-Nordic Seas exchanges. Prog. Oceanogr., 45, 109-208.

— and $\_$, 2007: Faroe Bank Channel overflow 1995-2005. Prog. Oceanogr., 75, 817-856.

Høyer, J. L., and D. Quadfasel, 2001: Detection of deep overflows with satellite altimetry. Geophys. Res. Lett., 28, 1611-1614.

Jiang, L., and R. W. Garwood, 1996: Three-dimensional simulations of overflows on continental slopes. J. Phys. Oceanogr., 26, 1214-1233.

Johns, W. E., and D. R. Watts, 1986: Time scales and structure of topographic Rossby waves and meanders in the deep Gulf Stream. J. Mar. Res., 44, 267-290.

Käse, R. H., J. B. Girton, and T. B. Sanford, 2003: Structure and variability of the Denmark Strait Overflow: Model and observations. J. Geophys. Res., 108, 3181, doi:10.1029/2002JC001.

Kida, S., J. Y. Yang, and J. F. Price, 2009: Marginal sea overflows and the upper-ocean interaction. J. Phys. Oceanogr., 39, 387403.

Lane-Serff, G. F., and P. G. Baines, 1998: Eddy formation by dense flows on slopes in a rotating fluid. J. Fluid Mech., 363, 229-252.

Mauritzen, C., J. Price, T. Sanford, and D. Torres, 2005: Circulation and mixing in the Faroese Channels. Deep-Sea Res. I, 52, 883-913.

Mortensen, E., M. Larsen, B. Hansen, R. Kristiansen, and S. Østerhus, 2009: Nordic WOCE ADCP deployments in Faroese Waters 2008-2009. Faroe Marine Research Institute Havstovan Tech. Rep. 09-05, 76 pp.

Nof, D., 1983: The translation of isolated cold eddies on a sloping bottom. Deep-Sea Res., 30A, 171-182.

, N. Paldor, and S. Van Gorder, 2002: The reddy maker. DeepSea Res. I, 49, 1531-1549.

Østerhus, S., T. Sherwin, D. Quadfsel, and B. Hansen, 2008: The overflow transport east of Iceland. Arctic-Subarctic Ocean Fluxes Defining the Role of the Northern Seas in Climate, 
R. Dickson, J. Meincke, and P. Rhines, Eds., Springer, 427443.

Pavec, M., X. Carton, and G. Swaters, 2005: Baroclinic instability of frontal geostrophic currents over a slope. J. Phys. Oceanogr., 35, 911-918.

Pedlosky, J., 2003: Waves in the Ocean and Atmosphere: Introduction to Wave Dynamics. Springer-Verlag, 260 pp.

Phillips, N., 1954: Energy transformations and meridional circulations associated with simple baroclinic waves in a two-level quasi-geostrophic model. Tellus, 6, 273-286.

Pickart, R. S., 1995: Gulf Stream-generated topographic Rossby waves. J. Phys. Oceanogr., 25, 574-586.

—, and D. R. Watts, 1990: Deep western boundary current variability at Cape Hatteras. J. Mar. Res., 48, 765-791.

Pratt, L. J., K. R. Helfrich, and D. Leen, 2008: On the stability of ocean overflows. J. Fluid Mech., 602, 241-266.

Quadfasel, D., and R. Käse, 2007: Present-day manifestation of the Nordic Seas overflows. Ocean Circulation: Mechanisms and Impacts: Past and Future Changes of the Meridional Overturning, Geophys. Monogr., Vol. 173, Amer. Geophys. Union, 75-90.

Rhines, P., 1970: Edge-, bottom-, and Rossby waves in a rotating stratified fluid. J. Fluid Mech., 1, 273-302.

Riemenschneider, U., and S. Legg, 2007: Regional simulations of the Faroe Bank Channel overflow in a level model. Ocean Modell., 17, 93-122.

Saunders, P. M., 1990: Cold outflow from the Faroe Bank Channel. J. Phys. Oceanogr., 20, 29-43.

- 2001: The dense northern overflows. Ocean Circulation and Climate: Observing and Modelling the Global Ocean, G. Siedler, J. Church, and J. Gould, Eds., International Geophysics Series, Vol. 77, Academic Press, 401-418.

Seim, K. S., and I. Fer, 2011: Mixing in the stratified interface of the Faroe Bank Channel overflow: The role of transverse circulation and internal waves. J. Geophys. Res., 116, C07022, doi:10.1029/2010JC006805.

,-- , and J. Berntsen, 2010: Regional simulations of the Faroe Bank Channel overflow using a sigma-coordinate ocean model. Ocean Modell., 35 (1-2), 31-44.

Sherwin, T. J., M. O. Williams, W. R. Turrell, S. L. Hughes, and P. I. Miller, 2006: A description and analysis of mesoscale variability in the Faroe-Shetland Channel. J. Geophys. Res., 111, C03003, doi:10.1029/2005JC002867.

Smith, P. C., 1976: Baroclinic instability in Denmark Strait Overflow. J. Phys. Oceanogr., 6, 355-371.

— 1977: Experiments with viscous source flows in rotating systems. Dyn. Atmos. Oceans, 1, 241-272.

Spall, M. A., and J. F. Price, 1998: Mesoscale variability in Denmark Strait: The PV outflow hypothesis. J. Phys. Oceanogr., 28, 1598-1623.

Swaters, G. E., 1991: On the baroclinic instability of cold-core coupled density fronts on a sloping continental-shelf. J. Fluid Mech., 224, 361-382.

Tanaka, K., 2006: Effects of the Earth's rotation and bottom slope on a density current descending a sloping bottom. J. Geophys. Res., 111, C11018, doi:10.1029/2006JC003677.

— , and K. Akitomo, 2001: Baroclinic instability of density current along a sloping bottom and the associated transport process. J. Geophys. Res., 106 (C2), 2621-2638.

Voet, G., and D. Quadfasel, 2010: Entrainment in the Denmark Strait overflow plume by meso-scale eddies. Ocean Sci., 6, 301-310.

Wåhlin, A. K., and G. Walin, 2001: Downward migration of dense bottom currents. Environ. Fluid Mech., 1, 257-259.

— , E. Darelius, C. Cenedese, and G. F. Lane-Serff, 2008: Laboratory observations of enhanced entrainment in dense overflows in the presence of submarine canyons and ridges. Deep-Sea Res. I, 55, 737-750. 